\title{
The legacy of Drosophila imaginal dises
}

\author{
Jorge V. Beira ${ }^{1} \cdot$ Renato Paro ${ }^{1,2}$
}

Received: 18 December 2015 /Revised: 12 April 2016/Accepted: 21 April 2016/Published online: 7 May 2016

(C) The Author(s) 2016. This article is published with open access at Springerlink.com

\begin{abstract}
The study of Drosophila imaginal discs has contributed to a number of discoveries in developmental and cellular biology. In addition to the elucidation of the role of tissue compartments and organ-specific master regulator genes during development, imaginal discs have also become well established as models for studying cellular interactions and complex genetic pathways. Here, we review key discoveries resulting from investigations of these epithelial precursor organs, ranging from cell fate determination and transdetermination to tissue patterning. Furthermore, the design of increasingly sophisticated genetic tools over the last decades has added value to the use of imaginal discs as model systems. As a result of tissue-specific genetic screens, several components of developmentally regulated signaling pathways were identified and epistasis revealed the levels at which they function. Discs have been widely used to assess cellular interactions in their natural tissue context, contributing to a better understanding of growth regulation, tissue regeneration, and cancer. With the continuous implementation of novel tools, imaginal discs retain significant potential as model systems to address emerging questions in biology and medicine.
\end{abstract}

Keywords Drosophila $\cdot$ Imaginal discs $\cdot$ Patterning ·

Regeneration · Tumor model

Renato Paro

renato.paro@bsse.ethz.ch

1 Department of Biosystems Science and Engineering, ETH Zürich, Mattenstrasse 26, 4058 Basel, Switzerland

2 Faculty of Science, University of Basel, Klingelbergstrasse 50, 4056 Basel, Switzerland

\section{Introduction}

The initial discovery and molecular characterization of numerous gene products, known to play key roles in human physiology and medicine, were first described in fruit flies. Indeed, detailed genetic analyses in Drosophila revealed when and where many genes are required for developmental and cellular processes, and thus furthered our understanding of conserved molecular mechanisms. The amenability of Drosophila to carry out genetic screens, given the short generation time and considerable number of progeny, remains one of the main advantages of this model organism. While many genes have been identified through embryonic mutant screens, the characterization of critical gene function at different developmental stages has substantially benefitted from studies in imaginal discs. These structures are epithelial tissues that develop during the earlier stages of the life cycle in holometabolous insects and ultimately give rise to major adult body parts such as eyes, wings, legs, or genitalia.

Imaginal discs have provided a useful platform for studying fundamental aspects of biology, mainly due to their accessibility and the development of ingenious methods to manipulate the genetic content of cell populations within discs. Critically, the shared similarities of disc cells with the epithelial cells that protect most human organs highlights the relevance of discoveries made with imaginal discs for biomedical research (Jennings 2011; Wangler et al. 2015). The use of imaginal discs as experimental systems overcomes the limitations of lethal embryonic mutations, because patches of mutant tissue can be generated and analyzed at later developmental stages. Indeed, significant technical advances have contributed to these achievements, mainly due to targeted or tissuespecific expression of a construct of interest (with the GAL4/UAS system) and its possible combination with the generation of homozygous mutant clones within a wild-type 
tissue (with Flp/FRT) (Brand and Perrimon 1993; Chou and Perrimon 1992, 1996; Golic and Lindquist 1989).

This review is part of a series celebrating the work of Walter Gehring. He was first exposed to the biology of imaginal discs as a graduate student with Ernst Hadorn in Zurich, where he studied the capabilities of antennal imaginal discs to change fate (transdetermine). A desire to elucidate the mysteries of antenna-to-leg reprogramming observed in these early disc transplantation experiments and his concomitant identification of a Drosophila homeotic gene phenocopying this particular transformation provided the driving force behind his outstanding research career. This eventually led to the molecular characterization of the Antennapedia gene and the groundbreaking discovery of the homeobox, providing the basis for a new concept in developmental biology and highlighting extraordinary evolutionary conservation at the molecular level. Throughout his career, Walter Gehring treasured the advantages of imaginal discs for studying developmental processes and his legendary skills in genetically manipulating or transplanting discs inspired many scholars to continue the use of this exceptional experimental paradigm.

Here, we review a number of key discoveries made possible through experiments in imaginal discs as well as describe current topics and active research areas that benefit from discs as experimental systems. We bring together a wide range of fundamental concepts and discoveries, which are usually kept disconnected in topic-centered reviews, to ultimately showcase the importance of imaginal discs. We aim to provide an integrated perspective that connects key discoveries, such as cell determination, transdetermination, the homeobox, and the genetic control of development. We build upon these topics to further connect conserved signaling cascades functioning during normal development and regeneration to how their derailment permits tumor initiation. We also provide a succinct overview of genetic methods and clever tools available for disc manipulation, which have recently permitted sophisticated experiments for elucidating basic concepts of tissue regeneration and cancer. Discs serve as a canvas to experimentally address how cells and tissues respond to gain or loss of specific gene functions. The potential of using imaginal discs to aid future discoveries remains unchallenged, thus promising further contributions in cell and developmental biology.

\section{The development of imaginal discs and their embryonic origin}

In order to fully appreciate the contributions of imaginal discs and their lasting impact on modern biology, it is important to first provide some background about their development from embryonic tissues. During development, many organisms first develop miniature versions of their adult body structures, which eventually increase in size. However, Drosophila undergo substantial morphological changes during the life cycle, forming precursor structures during earlier molting stages that will not simply grow but be substantially transformed during metamorphosis. Adult flies have well-developed appendages (eyes, wings, legs, halteres, and genitals), while larvae require less complex structures for simple behaviors such as feeding or foraging. The structures that will give rise to external appendages in the adult remain protected within the larva. These precursor structures are referred to as "imaginal," as they will give rise to the adult body structures known as the "imago." Imaginal structures are not limited to the epidermal sac-like cell clusters known as discs but also include histoblast nests, which will form the abdominal epidermis, and other small groups of cells of the gut or salivary glands (Cohen 1993; Lawrence 1992).

In total, there are 19 discs in the larva, with nine bilateral pairs that will form epidermal structures, and a genital medial disc (Held 2005) (Fig. 1). Labial and clypeolabral discs will form the mouthparts. Eye-antennal discs will give rise to the compound eye and the antenna, and are in close contact with the mouth hooks and the optic lobes of the central nervous system. The three pairs of leg disc primordia arise in the embryo from the ventral ectoderm, one pair per thoracic segment (first-leg discs in T1 and second- and third-leg discs in T2 and T3, respectively) (Cohen 1993). Each thoracic segment also produces a pair of dorsal imaginal discs, namely humeral (or dorsal prothoracic), wing, and haltere discs. Finally, the genitalia arise from a medial disc spanning abdominal segments A8 to A10 and are sexually dimorphic, thus having distinct morphology and growth in males and females (Chen and Baker 1997; Estrada et al. 2003; Held 2005; Sánchez and Guerrero 2001).

Each imaginal disc arises from a cluster of few cells in the embryo, and the morphology matures during larval stages. The embryonic epidermis is formed by epithelial cells, which have a characteristic apico-basolateral architecture that is key for their function. The apical domains of disc cells face the lumen, and cell-cell adhesion enables epithelia to serve as a protective barrier. Disc experiments have formed our understanding of the protective barrier function of the epithelia, since they surround most organs across species. Imaginal discs become sac-like structures upon invagination from the embryonic ectoderm. Discs have an outer layer, the peripodial membrane, with squamous cells that provide little contribution to the cuticular structures in the adult (Haynie and Bryant 1986; Held 2005). The disc proper is formed by a single columnar epithelial layer, which confers advantages for imaging and analysis of structural changes in tissue and cell shape upon manipulations. Most discs also contain some adepithelial cells (mesodermal myoblasts), as well as tracheal cells and a few neurons that all reside between the epithelium and the basal lamina. The genital disc is the only case where 


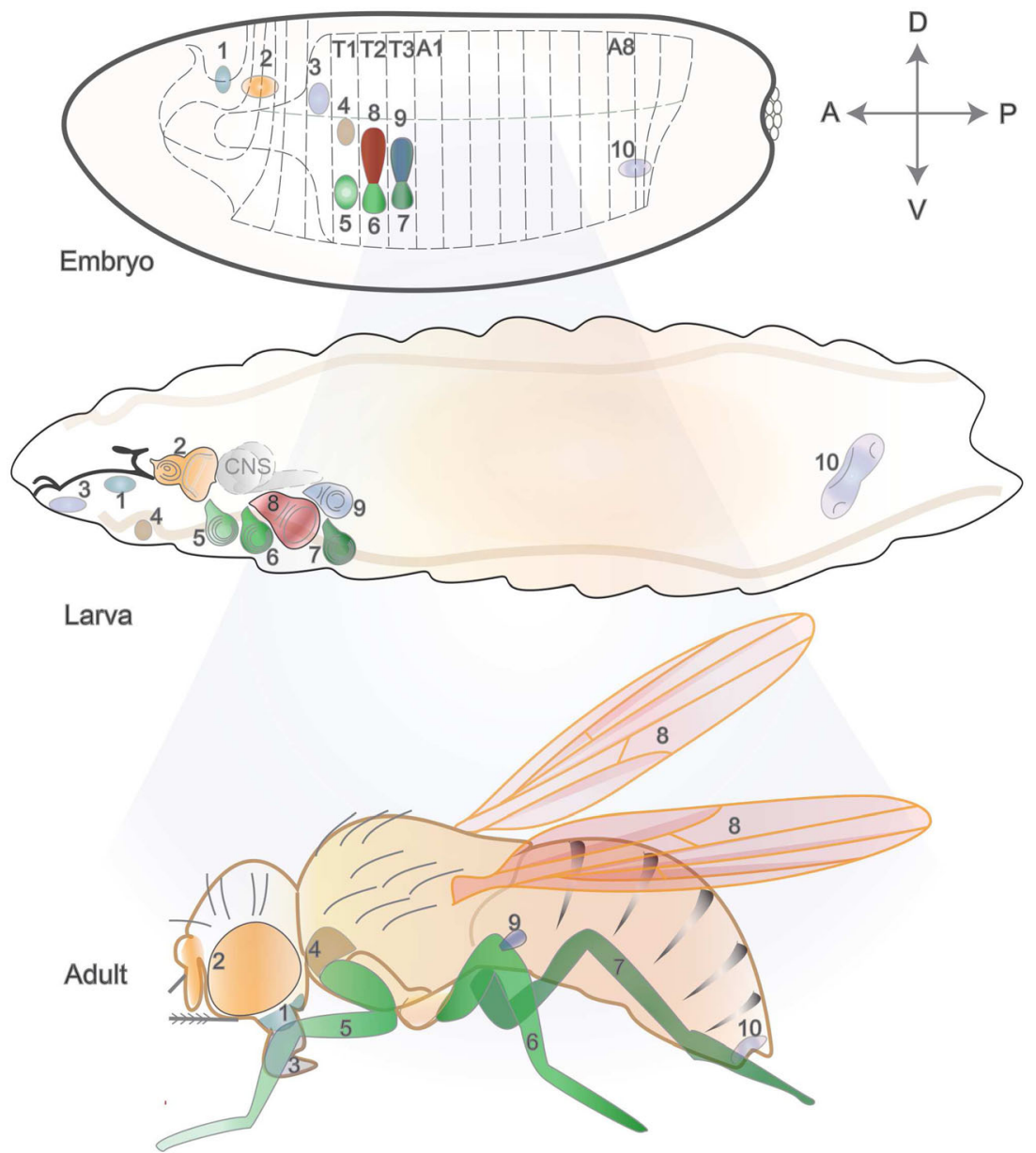

Fig. 1 Imaginal discs, their embryonic primordia, and adult cuticular products. The location of imaginal tissue primordia is represented at the cellular blastoderm stage (top), with corresponding numbering in larval (middle) and adult (bottom) stages. Axes orientation is indicated by the perpendicular arrows ( $A$ anterior, $P$ posterior, $D$ dorsal, $V$ ventral). $T 1$ to $T 3$ represent thoracic segments, and $A 1$ to $A 8$ correspond to abdominal segments. The epidermis of adult structures like the head, thorax, and appendages come from 9 pairs of bilateral discs (here, only one of each pair is shown in the larva), and genitals derive from a middle disc (19 discs in total): 1 , clypeolabral; 2 , eye-antennal; 3, labial; 4 , humeral (or prothoracic); 5 , first leg; 6 , second leg; 7, third leg; 8 , wing; 9, haltere; 10 , genital. Note that some portions of the head and thorax, including the notum, also originate from imaginal discs. For instance, the wing discs contribute both to the wings and the notum in the adult fly, which is not represented here for simplicity. Parts of the figure were inspired by (Held 2005), where additional details are described cells from the mesoderm are recruited into the epithelium (Held 2005). In a newly hatched first instar larva (about $24 \mathrm{~h}$ after egg laying, AEL), the larger discs (wing, leg, and eyeantennal) contain about 20-70 cells (Madhavan and Schneiderman 1977). By mid-to-late first instar, disc cells resume mitosis and continue dividing exponentially during second and third instar stages (Cohen 1993; Nöthiger 1972). Notably, a considerable number of cells appear during the third instar, with cell number doubling about every $10 \mathrm{~h}$. Prior to pupariation, each disc contains from 10,000 to 50 , 000 cells (Johnston et al. 1999; Morata and Ripoll 1975).

Mature discs undergo a major morphogenetic event during metamorphosis, as they evert through their stalk in a process that is triggered by the ecdysone hormonal cascade (Fristrom and Fristrom 1993; Poodry 1980). Recent imaging and culturing methods have opened the path to document this process using live imaging of fluorescently labeled portions of the wing disc. The dynamics of such morphogenetic movements have been described and include a $90^{\circ}$ folding of the disc followed by a rapprochement with the pupal epidermis and finally the disintegration of the peripodial membrane by apoptosis (Aldaz et al. 2010). Whole-tissue imaging further refined this process by following groups of fluorescently marked cells through the epidermis of the developing larva, avoiding the need for dissection (Kanca et al. 2014). This brief overview of imaginal disc development sets the basis for the main purpose of revisiting key discoveries with discs that had a lasting impact in modern biology and across species. For a more comprehensive overview of imaginal disc development, see for example (Cohen 1993; Held 2005). 


\section{From fate mapping to transdetermination}

Because the origins of imaginal discs can be traced back to specific positions in the embryo, this experimental system has historically been useful for fate mapping. More specifically, experimental embryologists observed that localized damage to the embryo could have an effect on specific structures of the adult (Gehring 1972; Postlethwait and Schneiderman 1973). Furthermore, disc primordia from embryo fragments could be cultured in vivo, transplanted to larval hosts, and, upon metamorphosis, grow to their approximate normal size and show normal spatial patterns (Schubiger et al. 1969). Studies by Ernst Hadorn and colleagues established imaginal disc transplantation techniques, which led to the creation of fate maps and provided information about the organization of the mature disc (Hadorn 1965; Schubiger and Schubiger 1978; Schubiger et al. 2012). The cell potential (or determination) was assessed by the variety of structures that would arise from the transplanted tissue, indirectly revealing cell fate restriction or plasticity.

The subject of cell determination received considerable attention in the pre-molecular era and benefitted greatly from the burgeoning field of molecular biology. Genetic studies showed that discs originate as groups of founder cells, known as polyclones (Crick and Lawrence 1975). Garcia-Bellido and Merriam used gynandromorphs (flies that are sexual mosaics, composed of male and female tissues due to the loss of one $\mathrm{X}$ chromosome during early cleavages) to ask if discs originated from a single cell, having only one sex. This was not the case, and together with transplantation studies using eye-antennal, leg, wing, haltere, and genital discs, it became clear that imaginal discs are of multicellular origin (Garcia-Bellido and Merriam 1969; Wieschaus and Gehring 1976). Transplantation of single cells from the embryo tested the possibility of reprogramming of cellular fate according to the location where they would be placed, yet cells could retain their parasegmental identity following transplantation. Transplantation of beta-galactosidasemarked cells from a blastoderm stage embryo tested the contribution of clones originating from injected cells. These were found to contribute to both larval and imaginal structures, demonstrating that no lineage restriction exists at this stage and, thus, that imaginal identity is established later (Vincent and O'Farrell 1992). These experiments also resolved issues about tissue compartments, as described in the next section.

While performing serial transplantation experiments, Hadorn witnessed an unexpected observation: despite transplanting genital discs, he noticed the later appearance of ectopic antennal tissue as a result of a process which was then termed transdetermination (Gehring 2002; Hadorn 1965; Nöthiger 2002). This propensity was later shown to occur with other discs displaying eye-to-wing or leg-to-wing transformations. Moreover, it was realized that cutting discs through sensitive regions yielded transdetermination events at higher frequencies (Fig. 2) (Schubiger 1971; Worley et al. 2012). Some of the molecular players involved in transdetermination are similarly crucial for the regenerative process in wounded tissues, and thus, a parallel has been suggested between the molecular mechanisms regulating transdetermination and regeneration (Bergantiños et al. 2010b) (as discussed in more detail below). Experiments based on disc fragmentation and transplantation contributed to addressing issues of cell determination and transdetermination. These initial studies provided a basis for branching questions, such as cellular plasticity, regeneration, or maintenance of cell identity.

\section{Compartments and patterning signals in imaginal tissues}

The concept of tissue patterning lies at the core of understanding organ development, since it provides the initial cues necessary for genetic cascades to produce shape and function at later stages. The basic rules underlying patterning and the organization of the body plan were revealed as a result of combining molecular biology techniques with genetics, a step forward that considerably expanded developmental genetics. Sequential activities of gene networks establish individual segments along the anterior-posterior axis of the fly embryo. In turn, these patterning signals are integrated with instructions from Hox genes whose downstream targets include morphogens like wingless $(w g)$, hedgehog $(h h)$, or decapentaplegic (dpp) (Jaeger 2011; Lawrence and Struhl 1996; Morata 2001; Scott and Carroll 1987). Individual segments will thus develop distinct features, resulting from differential transcriptional programs in response to a specific combination of signals. While imaginal disc patterning differs in some aspects from anteriorposterior patterning in embryonic segments, several players are common to both stages and throughout appendage development.

At the molecular level, presumptive disc cells in the embryo already express genes like distal-less $(D l l)$, vestigial ( $v g$ ), escargot (esg), and snail (sna) that will later be required not only for normal disc development but also at later stages (Cohen et al. 1993, 1991; Cohen 1990; Ray et al. 1991; Whiteley et al. 1992; Williams et al. 1991). For instance, ventral (leg) discs initially form in the ventral ectoderm and can be identified by expression of the homeotic gene Dll. Whereas the presumptive dorsal disc cells (wing and haltere) express $v g$, and these discs invaginate from the epidermis during dorsal closure (Cohen 1993; Williams et al. 1991). The embryonic cells that will give rise to thoracic imaginal discs are stereotypically located where the expression of $w g, d p p$, and 


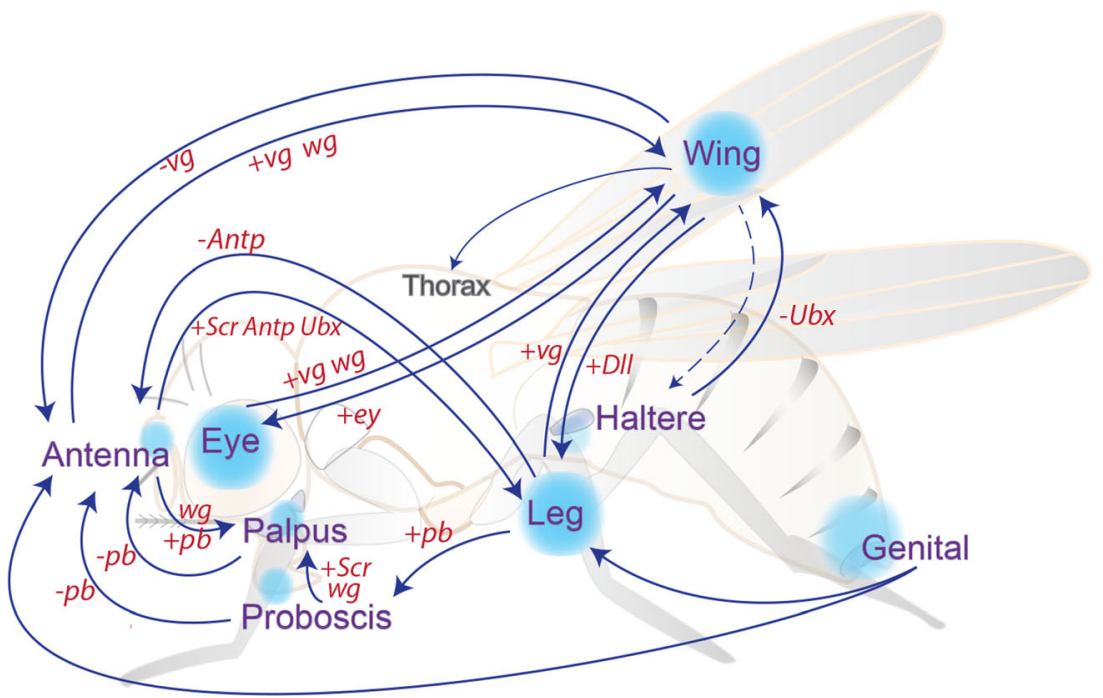

Fig. 2 An overview of transdetermination events, resulting both from disc fragmentation and through genetic manipulations. Classical transdetermination events occur with some probability upon disc fragmentation and culture through transplantation, some with higher frequencies like leg-to-wing (see main text). Ectopic expression of $w g$ (wingless) also results in transdetermination in situ, similarly to what seems to occur at "weak points," where endogenous high levels of Wg and Dpp have been linked with switches in cell fates. Genetic manipulations also recapitulate transdetermination of some fly tissues into distinct ones (arrows connecting the blue circles), specifically by gain $(+)$ or loss $(-)$ of homeotic or selector gene expression (Ubx, Ultrabithorax; Antp, Antennapedia; pb, proboscipedia; Scr, Sex combs reduced; ey, eyeless; Dll, distal-less; vg, vestigial). The figure was inspired by Wei et al. (2000) and McClure and Schubiger (2007) engrailed intersects (Cohen et al. 1993). The expression of $d p p$ in the embryo is perpendicular to that of the segment polarity genes $w g$ and engrailed (en), a feature that is also observed, for example, in the wing disc. Engrailed is expressed in the posterior region of both embryonic segments and imaginal discs, where it not only functions as a selector gene but also defines tissue compartmentalization, a concept further examined below. It became clear that anterior-posterior (A-P) boundaries in imaginal discs reflect earlier lineage restriction and are initially established as parasegment boundaries in the embryo (Dahmann and Basler 1999; MartinezArias and Lawrence 1985).

The discovery of tissue compartments was revealed by clonal analysis, which also proved very fruitful for fate mapping and lineage tracing. Compartments are the result of a lineage restriction between the anterior and posterior portions of the wing disc (Garcia-Bellido et al. 1973; Morata and Lawrence 1975). Such restriction occurs early in the Drosophila embryo, where all segments contain two separate lineages, anterior and posterior, which are segregated and form a stable boundary throughout development. For instance, when clones are genetically induced, they can arise in either compartment, but they do not cross from one to the other. The concept of tissue compartments had broader implications for understanding development in other organisms, since they were later found to similarly exist in the developing chicken hindbrain and the mammalian brain (Dahmann and Basler 1999; Fraser et al. 1990; Ingham and Arias 1992; Levitt et al. 1997).
The molecular mechanisms underlying allocation of cell fates among anterior and posterior identities were found to require a key gene, engrailed (Morata and Lawrence 1975). Clonal experiments uncovered a role for en in the selection of posterior identity. Clones lacking en in the posterior compartment develop into anterior structures and no longer respect the boundary, while mutant clones arising in the anterior compartment develop normally. Furthermore, an ectopic boundary formed in the $\mathrm{P}$ compartment at the interface between wild-type posterior cells and engrailed mutant clones, which behave as anterior cells (Lawrence and Struhl 1996; Morata and Lawrence 1975). These results from clonal analyses, together with the observation that wings of adult flies lacking en exhibit transformation to anterior structures, clarified the role of en as a selector gene. In addition to the A-P compartment boundary, a second tissue division appears during larval stages, at the dorsal-ventral (D-V) border. In the case of this orthogonal subdivision, the selector gene apterous was identified to establish the differences in dorsal-ventral identities and also to play a role in wing growth and patterning (Diaz-Benjumea 1993).

The wing imaginal disc proved ideal to uncover the molecular relationships between patterning regulators, as within this, tissue morphogens play a role in both the A-P and D-V axes, which intersect perpendicularly in the pouch region. The same cascades also function in other discs, as illustrated in Fig. 3. Engrailed inhibits Hedgehog signaling in the posterior compartment, but Hh secretion permits short-range signaling 

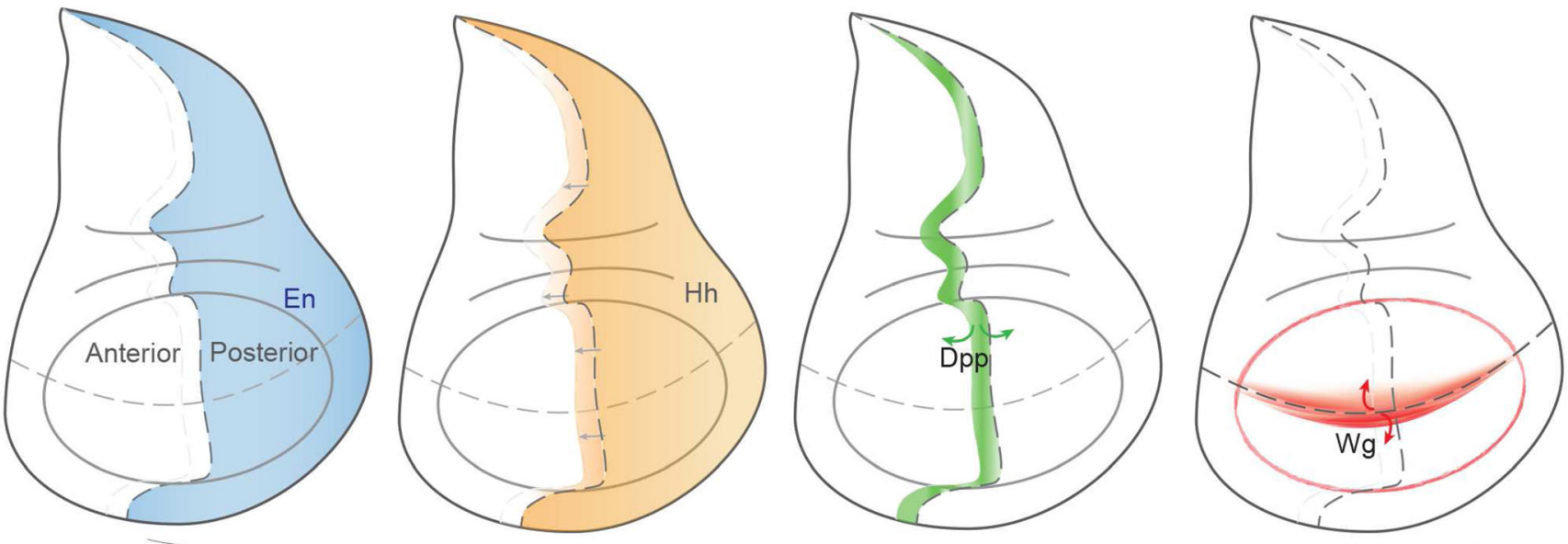

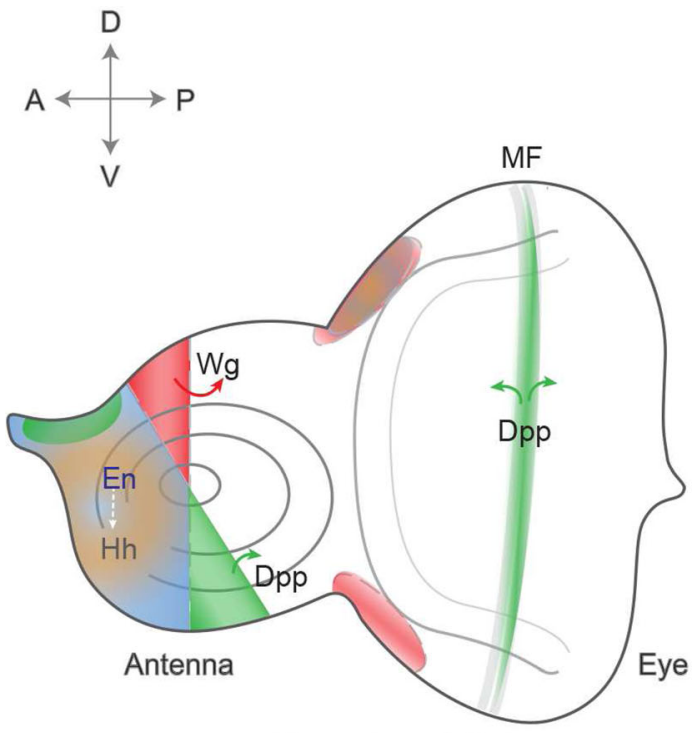

Eye-antennal disc

Fig. 3 Expression domains of key signaling and patterning pathways in wing, eye-antennal, and leg discs. Imaginal discs become subdivided and patterned during development, under the concerted action of signaling pathways and morphogens. Four key signals are represented individually in the wing disc (top). Engrailed (en) is expressed in all cells in the posterior $(P)$ compartment, conferring posterior identity and thus establishing the anterior-posterior $(A-P)$ boundary. En directs expression of the secreted short-range signaling molecule, Hedgehog $(H h)$, which can cross the A-P boundary and induce expression of Decapentaplegic $(D p p)$. Dpp is expressed along the A-P boundary, and

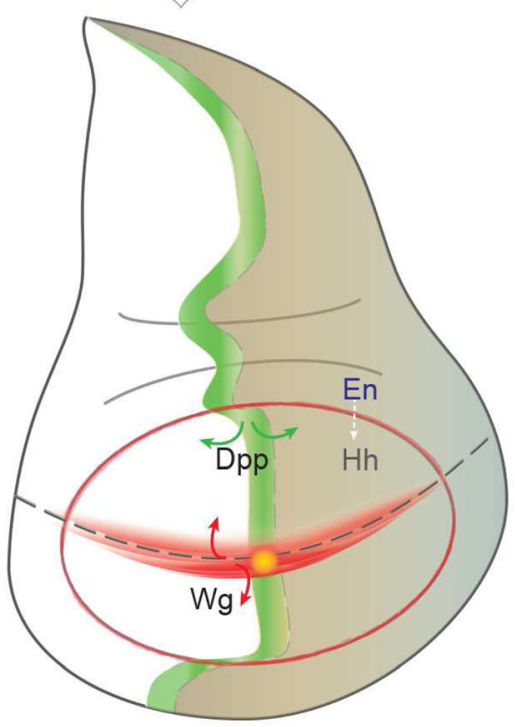

Wing disc

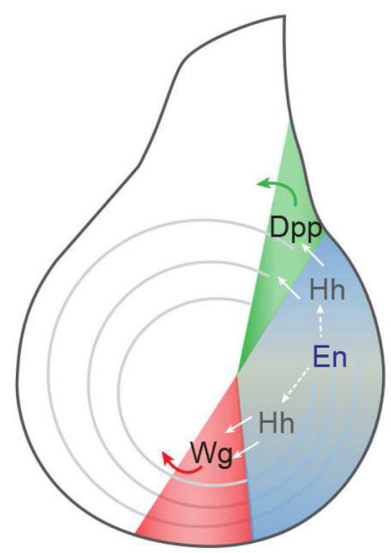

Leg disc

its secretion permits long-range signaling to direct patterning of a wider disc region. Wingless $(W g)$ is produced at the dorsal-ventral $(D-V)$ boundary, a signal that is also key for wing development (see main text). The signaling domains are represented all together in the bottom central wing disc, and their roles are also similarly conserved in other tissues, like the eye-antennal (bottom left) and leg (bottom right) discs. A similar color coding is used in all discs, which are oriented with anterior to the left and dorsal up. Expression patterns at other developmental stages are described in Held (2005)

axes in insect appendages, leading to the activation of proximal selector genes that confer appendage identity, such as vestigial and scalloped in the wing. The pioneering research connecting compartment boundaries to the proximal-distal patterning axis in fly imaginal discs has illuminated important aspects of vertebrate limb development as many basic rules operating in this system are shared in distantly related organisms (Brook et al. 1996; Dahmann et al. 2011). For a comprehensive description of the molecular determinants involved in appendage development, see for example Mann and Morata (2000) and Morata (2001). 
The functional relevance of tissue compartments became more apparent with the finding that the domain of action of some homeotic genes was also restricted. Homeotic transformations refer to alterations of specific body segments or structures and are the phenotypic manifestation of mutations in homeotic genes. For example, a spontaneous homeotic mutation led to transformation of the anterior portion of the third thoracic segment (aT3) into the anterior portion of the second (aT2) and was named bithorax ( $b x$, later found to be an allele of $U b x)$. Another mutation with a complementary effect was also isolated, postbithorax ( $p b x)$, where the posterior part of T3 (pT3) is transformed into pT2. The combination of bx and $p b x$ mutations by meiotic recombination enabled Ed Lewis to produce the famous four-winged fly, where a second pair of wings develops instead of halteres, showcasing a functional consequence of mutations in the bithorax complex (BX-C) (Lewis 1978). For a comprehensive discussion of the bithorax complex, see another review in this series (Maeda and Karch 2015). Another homeotic transformation that was identified, among several, was Antennapedia where legs develop instead of antennal structures, thus naming a second Hox gene complex, ANT-C (Schneuwly and Gehring 1985).

The realization that many genes implicated in development and cell fate decisions contained a homeobox established a shared principle for regulation relying on transcriptional changes. More explicitly, the combinatorial activities of homeobox genes result in distinct cell fates in specific tissues and organs (Struhl 1982). The strict regulation of Hox gene expression in specific segments or compartments proved to be at the core of a faithful developmental program, as evidenced by homeotic phenotypes resulting from their dysregulation. The maintenance of ON or OFF states of homeobox genes in specific expression patterns was found to depend on Trithorax (TrxG) and Polycomb group (PcG) genes, respectively (Ringrose and Paro 2007). Although initially studied for their embryonic phenotype, their function is also crucial for cellular memory in imaginal discs, as early studies showed for some genes that are regulated by PcG/TrxG, like en, $h h$, or $w g$ (Ingham 1983; Maurange and Paro 2002; Paro and Hogness 1991; Randsholt et al. 2000). Molecular analyses made clear that PcG and TrxG proteins form multimeric complexes involved in epigenetic regulation, especially as they contain enzymatic activities responsible for catalyzing histone modifications, H3K27me3 by $E(z)$ or H3K4me3 by Trx (Beisel and Paro 2011; Byrd and Shearn 2003; Czermin et al. 2002; Müller et al. 2002). PcG/TrxG target several hundred genes (most of which are developmental regulators) and play a global role in chromatin regulation and genome architecture that is conserved in many species (Boyer et al. 2006; Schwartz et al. 2006; Sexton et al. 2012; Tolhuis et al. 2006). Thus, the Hox gene clusters were used as a starting point to identify the underlying regulatory mechanisms, resulting in far broader implications for global genome function and chromatin biology, a field that is currently sprouting aided by new methodologies.

\section{Studies on organ growth and shape, cellular interactions, and signaling cascades}

Alongside the identification of spontaneous mutations in some homeotic genes, screens for mutations affecting specific imaginal discs uncovered several classes of phenotypes, many affecting organ growth or shape (disc undergrowth, overgrowth, or even hyperplastic growth) (Cohen 1993; Shearn and Garen 1974). However, in general, these approaches only identified mutations causing local effects or those not leading to premature lethality because observing the phenotype required survival beyond embryonic stages. To overcome this limitation of whole organism mutations, successful genetic screens combined mutagenesis (with chemical mutagens, like ethyl methanesulfonate (EMS), or P-element-mediated mutagenesis) with genetic mosaic-inducing techniques, such as Flp/ FRT-mediated mitotic recombination. Such strategies permitted the characterization of gene function in restricted tissue patches (Chou and Perrimon 1996; Spradling and Rubin 1982; St Johnston 2002) (Fig. 4). Furthermore, clonal analysis enabled discrimination between cell-autonomous and noncell-autonomous effects to further clarify the importance of cellular interactions between mutant tissue and the surrounding "wild-type" tissue.

Imaginal discs have also been fundamental for characterizing the role of conserved signaling pathways in developing tissues. The amenability for epistasis experiments revealed the function of several pathway members in vivo and at what cascade levels they work. In addition to the main patterning signals mentioned before (Wg, Dpp, and $\mathrm{Hh}$ ), fly research has also been at the root of discoveries spanning many members of conserved signaling cascades such as Notch, EGFR (epidermal growth factor receptor), MAPK (mitogen-activated protein kinase), JAK-STAT (Janus kinase and signaling transducer and activator of transcription), JNK (Jun N-terminal Kinase), among others.

Defective eye specification revealed roles for transcription factors like eyeless, twin of eyeless (toy), eyes absent (eya), eyegone, sine oculis, and also Notch and EGFR signaling acting upstream of this transcriptional network (Kumar 2001). Interestingly, many members of this gene network responsible for the eye-antennal transcriptional program contain a homeobox, which is a recurring feature of transcription factors acting during development. Enhancer and suppressor screens revealed a number of components acting within the same pathways. For example, epistasis experiments clarified the role of spitz as a ligand that can bind to the Egf receptor (torpedo), leading to the activation of downstream kinases encoded by ras and raf and culminating in transcriptional regulation by 
Pointed (Kumar 2001; St Johnston 2002). Notch signaling can be triggered by ligands, such as Serrate and Delta, binding to the receptor (Notch) which, after cleavage of the intracellular domain by gamma-secretase, can partner with $\mathrm{Su}(\mathrm{Hw})$ (suppressor of hairy wing) to modulate transcriptional activation. For a more complete summary of Notch signaling, see Guruharsha et al. (2012). Importantly, bristle specification and imaginal disc experiments uncovered three Notch activities that established paradigms in neural development across species: cell fate assignment, boundary formation, and lateral inhibition (Bray 1998; Gómez-Skarmeta et al. 2003).

The global signaling rules employed by cells in a tissue are key to understanding how cells communicate with their immediate neighbors or even how distant intercellular interactions play a role in normal physiology. The in vivo function of a considerable number of newly identified signaling components was achieved through clonal or genetic experiments in Drosophila (which goes beyond the scope of this review) (Hynes et al. 2013; Jenny and Basler 2015; Kumar 2001). One of the central questions regarding the integration of different signaling instructions through cellular interactions concerns how growth control is achieved. Growth regulation has attracted considerable attention in the last decades and thus deserves some mention, as several genetic screens have identified regulatory genes.

Wg and Dpp are instrumental in wing disc patterning and growth, and have been classified as morphogens since both proteins can spread further away from the cells where the respective genes are expressed (Vincent and Briscoe 2001). It has been proposed that morphogen gradients are responsible for instructing growth and patterning of the wing disc and may have similar functions in vertebrates (Ashe and Briscoe 2006; Tabata 2001). For example, the Dpp gradient could lead to activation of distinct targets depending on the distance from the source (the A-P boundary), as suggested by the nested expression patterns of its target genes. Three wellcharacterized targets are spalt major (salm), optomotor blind $(o m b)$, and brinker (brk). While salm expression is centered around the source, the domain of $o m b$ expression is broader than salm, and brk is expressed at higher levels at the periphery, forming an opposing gradient to $d p p$ (Affolter and Basler 2007; Campbell and Tomlinson 1999; Nellen et al. 1996). Moreover, ectopic $d p p$-expressing clones could produce duplications of wing veins with correctly patterned territories (Capdevila and Guerrero 1994; Zecca et al. 1995). Similarly, the evidence for the existence of a $\mathrm{Wg}$ gradient was also supported by nested expression domains of targets described along the D-V boundary, e.g., senseless (sens, a high-level target), distal-less (Dll, with a more extended range), and $v g$ (a low-level target expressed in most of the prospective wing) (Neumann and Cohen 1997; Zecca et al. 1996). However, recent evidence challenges the requirement of a $\mathrm{Wg}$ gradient since flies carrying solely an engineered version of $w g$ that is
Fig. 4 Overview of clone-generating techniques. Three broadly used techniques relying on the Flp/FRT system, where the source of Flippase can be chosen depending on experimental design, e.g., commonly using the heat shock promoter with temporal control or tissue-restricted promoters (ey, Ubx). Top: after egg laying for a defined period and aging larvae to the desired stage, mosaics are induced upon Flp expression and, by dissecting the tissues of interest, the effect of genetic manipulations is analyzed by comparing clones with neighboring wildtype tissue. (1) Flp-out clones do not rely on mitosis, since Flp mediates recombination of two FRT (Flippase-Recognition Targets) elements with the same orientation located in close proximity in one chromosome. Usually, a constitutive promoter (actin, tubulin, etc.) is not active in the absence of Flp due to an element flanked by FRT sites (e.g. stop, or yellow marker). Excision of the flanked element upon Flp-dependent recombination enables the promoter to activate a downstream gene only within the clone (for example, a marker such as lacZ, Gal4 (that could activate a UAS-lacZ), or other alternatives). (2) Mitotic clones require cell division, where somatic recombination of chromosomes in heterozygous cells provides the opportunity for Flp-mediated recombination. In a given parental cell (heterozygous for a mutation of interest), recombination between matching FRT elements located in homologous chromosomal arms produces two daughter cells: one carrying two copies of the wildtype chromosome and another homozygous for the desired mutation. The following cell divisions will therefore generate two cell populations, hence a clone and its wild-type counterpart. A constitutive marker is often used (e.g., a ubiquitous GFP construct inserted in the wild-type chromosome), and thus the homozygous mutant clone can be identified by the absence of the marker (negatively marked), while the wild-type "twin" resulting from the same cell division (hence called twin spot) can also be visualized as it harbors two copies of the marker ( $2 x G F P)$. (3) An alternative method was developed to enable clones to be marked "positively," i.e., labeling the tissue harboring the desired genetic manipulation with GFP. This option is provided by MARCM (Mosaic Analysis with a Repressive Cell Marker), where the constitutive expression of a repressive component (Gal80) on the homologous chromosome prevents Gal4 from activating downstream genes or markers (usually UAS-GFP). Upon Flp expression, recombination produces a homozygous mutant cell that lacks Gal80 while the other contains a pair of FRT chromosomes carrying Gal80 (and no mutation). In the mutant clone, the absence of Gal 80 permits Gal4 to activate the UAS-GFP marker (and also permits further flexibility as other UAS transgenes can be expressed specifically within clones). In this case, the wild-type tissue remains unlabeled and only mutant clones are visually detected

unable to spread develop wings with nearly the right size and without apparent morphological defects (Alexandre et al. 2014). It has been suggested that cells expressing $w g$ at earlier stages maintain expression of target genes due to a cellular memory mechanism, even after the inducing signal is absent. Regarding Dpp, the role of this morphogen in tissue patterning and growth has attracted considerable attention, and a concentration-dependent response has been put forward to account for differences in size by affecting cell proliferation (Vuilleumier et al. 2010; Wartlick et al. 2011). Two recent studies, taking advantage of endogenous genome editing methods, suggest that the Dpp gradient is required for patterning but not essential for cell proliferation in lateral portions of the wing disc, thus contributing to growth mostly in the pouch region (Akiyama and Gibson 2015; Harmansa et al. 2015). All these reports showcase a topic of intense research that also has 


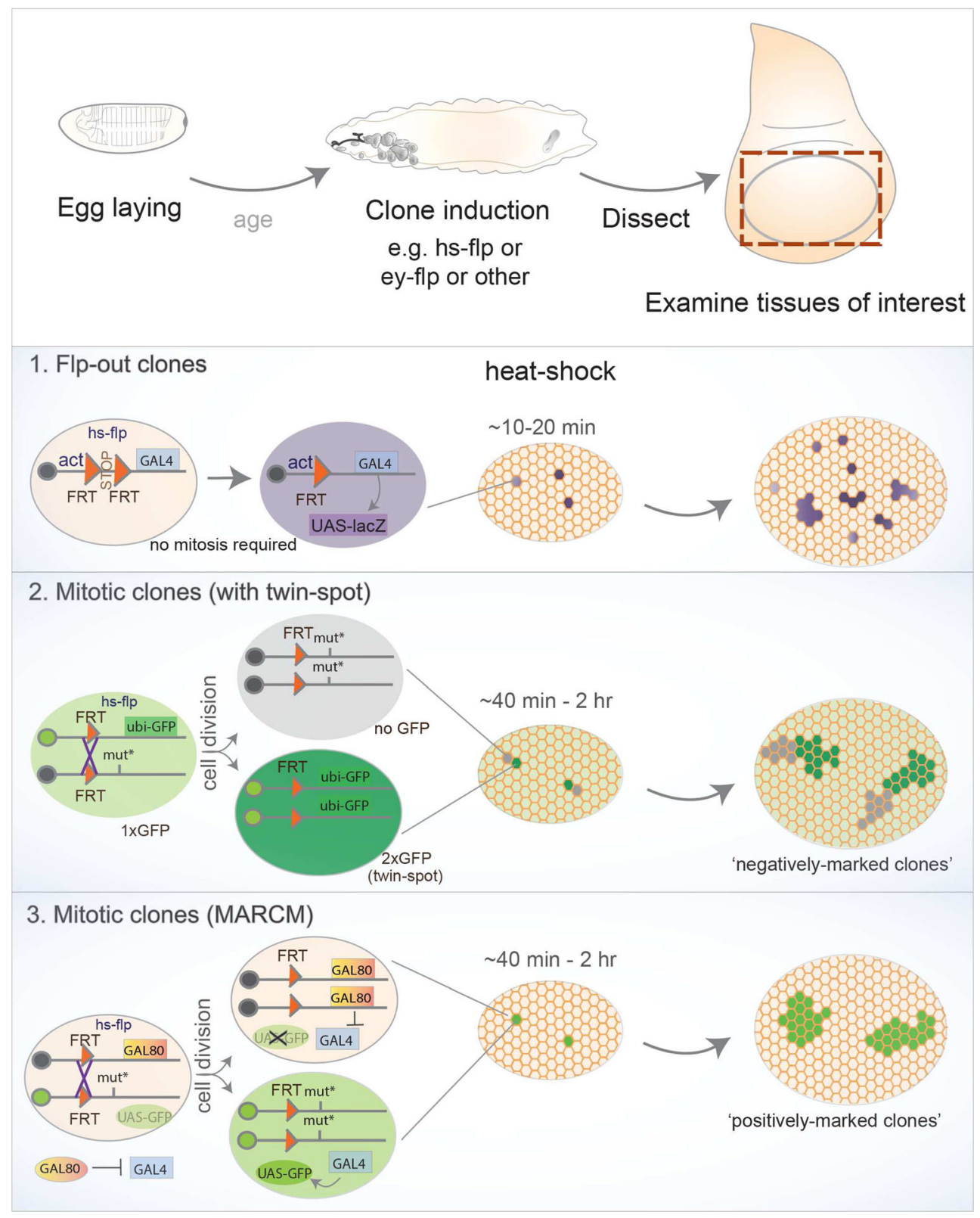

an impact beyond Drosophila, and thus, it will be interesting for future studies to determine how these observations and models will fit together.

Indeed, the wing disc became an established model for the study of morphogens and how they spread in tissues. For example, analogous patterning functions for Sonic Hedgehog ( $\mathrm{SHH}$, a homolog of $\mathrm{Hh}$ ) were uncovered during mammalian neural tube development (Kicheva et al. 2012). Moreover, mathematical modeling where physics concepts were applied to biological data from the wing Dpp gradient could generate hypotheses about gradient properties, and an "expander" protein (encoded by pentagone) has been suggested to enable scaling control (Ben-Zvi et al. 2011; Hamaratoglu et al. 2011). These examples demonstrate a variety of outcomes spanning several fields, as a result of a fundamental developmental question, yet with broad implications that are relevant across subjects and model systems.

Although Wg and Dpp (and the components of both pathways) assembled significant attention concerning growth regulation, alternative routes were taken to identify additional genes involved in these mechanisms. Genetic screens were carried out, for example, targeting the eye disc, producing large portions of homozygous mutant eye-antennal discs in an otherwise wild-type animal using site-specific recombination only in the target tissue. The eye disc proved a simple platform for such screens, as it does not affect fertility or viability, and phenotypes are easily assessed by comparing the mutant white patches to the wild-type "twin spots" originating from the same mitotic division (Fig. 4). For example, a version of the Flippase recombinase enzyme (engineered from 
yeast) only active in the eye-antennal disc (eyFlp) was used to induce recombination of FRT (Flippase-recognition target) sites, producing homozygous mutant tissue upon cell division. Screens were thus carried out using this approach with a wide range of mutations and led to the characterization of genes required for normal tissue architecture and growth. Examples of hits include the tumor suppressor kinases warts, salvador, and hippo, the latter giving its name to a novel pathway that can restrict cell proliferation and promote apoptosis (Tapon et al. 2002; Wu et al. 2003; Xu et al. 1995). Other initial screens for abnormal eye development revealed regulators of cell proliferation, like archipelago (through cyclin E) and homologs of the tuberous sclerosis complex (Tsc1/2). Likewise, cytoskeletal or nuclear components influencing cell affinity, adhesion, and eye development were also identified (Janody et al. 2004, 2003; Moberg et al. 2001; Tapon et al. 2001).

Sequencing of the fly genome and the discovery of RNA interference (RNAi) led to the generation of genome-wide transgenic RNAi libraries under UAS control, offering an unprecedented potential to precisely carry out selective reverse genetics using tissue-specific Gal4 drivers (Adams et al. 2000; Dietzl et al. 2007). These tools prompted the design of many genetic screens, either in the eye (with GMR-gal4) or wing compartments (en-gal4 or hh-gal4) where the effect of target gene knockdown could be directly compared to an internal control (e.g., the anterior compartment) where gene function remained intact. Such RNAi-based screens expanded our knowledge about further members of previously mentioned pathways (like Wg, Dpp, Notch, Hippo, etc.) and also finetuned our understanding of additional processes. For instance, screens uncovered regulators of apoptosis that could rescue small-eye phenotypes induced by downstream pro-apoptotic inducers (e.g., GMR $>$ hid) and compensatory proliferation (Fan and Bergmann 2008; Herz et al. 2006; MummeryWidmer et al. 2009; Saj et al. 2010; Thompson and Cohen 2006).

The previous examples of hits resulting from screens and clonal analyses in their complex tissue environments highlight the power of Drosophila discs as platforms to identify and characterize conserved factors and associated pathways, often for the first time. The foundation of detailed knowledge gathered on the basic biology of imaginal discs places us in an exciting position to further exploit these model systems to address medically relevant topics where developmental states are challenged, like regeneration and tumor initiation.

\section{From disc transplantation to tissue regeneration}

The process of tissue and organ regeneration has attracted curiosity for many decades. Classical examples of remarkable regenerative capacity come from amphibians, which are able to replace large and complex structures like the tail or limbs (Tanaka and Reddien 2011). The potential to build up on the basic knowledge underlying regenerative mechanisms for possible exploitation into medical applications has captivated many. Despite this profound interest, research using these organisms has been limited because few exploratory tools are available. Conversely, Drosophila stands at an interesting point for regenerative studies, since it is less complex than amphibians and humans and a wide palette of experimental tools is available.

The regenerative capacity of fly imaginal discs was noticed several decades ago alongside the transplantation experiments mentioned previously (Bryant 1971, 1975; Hadorn 1965). Upon disc fragmentation, for example, along the $\mathrm{D}-\mathrm{V}$ axis of the leg disc, the anterior portion can regenerate while the posterior half undergoes duplication where a mirror image of the tissue arises, instead of forming the missing part. Interestingly, the mechanism for this difference still remains a mystery (Bryant 1971; Schubiger 1971). The cells around the cut edges form a blastema containing cells that are able to divide more frequently than in other regions. These fast-proliferating cells are mainly responsible for disc regeneration, although cell death also occurs (Fig. 5) (Abbott et al. 1981; Kiehle and Schubiger 1985). The determination state of the disc seems to be maintained in blastema cells, yet when fragmentation occurs along defined "weak points," for example, where $d p p$ and $w g$ overlap, transdetermination events occur with some frequency (Johnston and Schubiger 1996; Maves and Schubiger 1995, 1999). Regeneration studies using disc fragmentation have, therefore, been tied with transdetermination (Worley et al. 2012).

The molecular events required for disc regeneration following fragmentation revealed a role for $\mathrm{Wg}$, as its ectopic expression frequently promoted leg-to-wing transdetermination (Johnston and Schubiger 1996). The molecular basis for transdetermination relies at least in part on interactions between Wg and Dpp signaling, as the activation of $v g$ downstream of $\mathrm{Wg}$ signaling resulted in the formation of more wing tissue from the dorsal region (where $d p p$ is higher) (Maves and Schubiger 1995, 1998). The function of these pathways in blastema cells may facilitate cellular plasticity underlying cell fate re-assignment during regeneration, and parallels with stem cell-like potency have been put forward (McClure and Schubiger 2007; Wei et al. 2000).

The micro-surgery techniques employed to study regeneration, for example, by dissecting the anterior quarter of the leg disc, trigger a wounding response at the early stages of blastema formation. Thus, the early regenerative response utilizes similar molecular routes as wound healing, involving the activation of stress signaling like JNK (Jun N-terminal kinase) (Bosch et al. 2005; Mattila et al. 2005). JNK is crucial at several stages of the regenerative response by directing cytoskeletal rearrangements to bridge the gap between wounded 


\section{Regeneration Models}
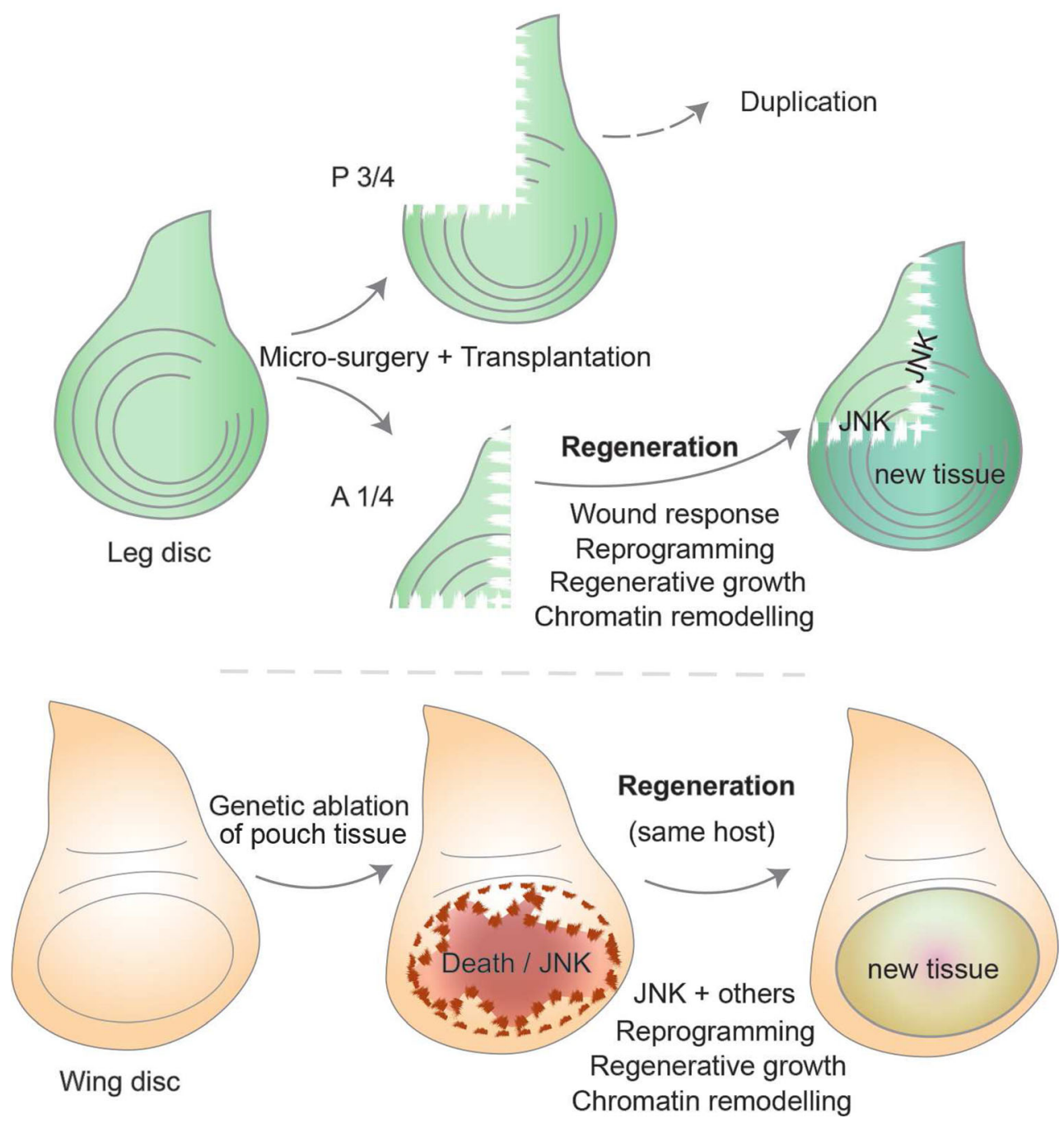

Fig. 5 Regeneration in Drosophila imaginal discs. Imaginal discs are able to regenerate upon micro-surgery and culture through transplantation to host flies. The leg disc has routinely been used in fragmentation experiments (top), often with a standard cut that separates the "anterior one quarter" from the "posterior three quarters." The larger fragment tends to result in tissue duplication, while the smaller fragment regenerates the remaining tissue with the correct pattern and function. The cut elicits a wounding-like response, followed by a phase of regenerative growth, for which chromatin remodeling is important during cellular reprogramming that can produce extra cells while maintaining the correct pattern and cellular identities. Recently developed tools (bottom) allow genetic-induced tissue ablation and regeneration within the same organism (overcoming the limitations of ablation and transplantation). Localized tissue ablation, for example, of the pouch region of the wing disc, can be spatially and temporally

tissues (similar to its function during embryonic dorsal closure (Martin and Parkhurst 2004)), by promoting cell death around the cut edges, and finally by modulating chromatin regulators. The latter function was uncovered as a result of inducing legto-wing transdetermination through ectopic $w g$ expression using the flp-out clonal technique (Struhl and Basler 1993). controlled. Different systems have been described (see main text), but generally, the design involves the following: a region-specific Gal4 is normally inhibited by ubiquitous Gal80 expression, which can be overcome by means of a temperature shift (with a temperature-sensitive form of Gal 80 that is inactive at $29^{\circ} \mathrm{C}$ or higher), which duration can be titrated to achieve specific conditions. During the period when Gal80 is inactive, Gal4 can activate a downstream UAS target that triggers apoptosis (e.g., using rpr, hid, egr, etc.). After an acute or controlled "damage-induction" phase, larvae are returned to a temperature that yields a functional Gal80 and thus inactivates the damage trigger, allowing tissues to regenerate during a "recovery" phase. Many of the hallmarks are conserved between the classical ablation experiments and the genetic-ablation systems, and the recent use of the latter promise considerable advantages that improve reproducibility and larger-scale experiments

This leads to $\mathrm{vg}$ expression in leg discs, which in turn results in transdetermination to wing tissue, of which frequency is increased upon JNK-mediated overcoming of PcG silencing (Lee et al. 2005). Since Polycomb group (PcG) proteins silence many developmental and signaling-related genes, the involvement of $\mathrm{PcG} / \mathrm{TrxG}$ links regenerative mechanisms 
with the regulation of powerful genes that confer tissue identity. Thus, transdetermination events can similarly require a selective bypass of PcG silencing of targets that select a distinct developmental program (as ectopic expression of tissuespecific selector genes can achieve similar results).

The use of modern transcriptomic approaches has revealed additional genes involved in regeneration. For example, Mmp1 and puckered (two targets of the JNK pathway) as well as those activated in response to stress and cell death-related genes become upregulated in regenerating discs (Blanco et al. 2010; Klebes et al. 2005; McClure and Schubiger 2008; McClure et al. 2008). Furthermore, additional chromatin factors were retrieved from transcriptome analyses, namely lama, $\mathrm{PcG} /$ TrxG, and chromatin remodelers such as the Brahma complex (Blanco et al. 2010; Klebes et al. 2005). The JAKSTAT pathway becomes activated through JNK-dependent upregulation of unpaired ligands and has, therefore, also been implicated in regeneration (Katsuyama et al. 2015). Interestingly, the signaling peptide dILP8 was upregulated in cut leg discs undergoing regeneration. Possibly providing the developmental delay required for healing and regeneration, dILP8 is known to induce a delay in when discs are damaged (Colombani et al. 2012; Garelli et al. 2012; Katsuyama et al. 2015).

The use of genetic tools that take advantage of tissuespecific drivers to trigger apoptosis in significant portions of imaginal discs has been employed in recent years to induce cell ablation and subsequent regeneration (Fig. 5). This has been achieved by either expressing effector pro-apoptotic genes, like hid or reaper, or upstream components that lead to JNK activation in a similar manner to what happens in the blastema (Bergantiños et al. 2010a; Herrera et al. 2013; SmithBolton et al. 2009). After a temperature-controlled time window for ablation (using gal80), the regenerative capacity of wing discs and the involvement of key pathways like Wg and Myc was then confirmed during a recovery period (SmithBolton et al. 2009).

Such genetic model systems are revitalizing studies on regeneration, since they offer significant advantages over microsurgery methods, not only improving reproducibility and increasing disc numbers for downstream analysis but also facilitating additional genetic manipulations or even screening. For example, an elegant study has recently revealed that compartment boundaries are transiently broken down, as the cells that contribute to disc regeneration were found in compartments outside of their origin (Herrera and Morata 2014). Fitting with previous observations, PcG and TrxG members also play a role in the process, by modulating the potential to transgress the A-P boundary. As cellular reprogramming has been regarded as an intrinsic aspect of the regenerative process, these results are among the first to test this hypothesis directly. Cell fate re-specification has also been reported, with regenerated veins having contributions from tissue that previously corresponded to inter-veins (Repiso et al. 2013). The reprogramming challenge poses some issues regarding developmental robustness, thus hinting that the regenerative process is likely very tightly regulated ensuring accurate repatterning and growth. The mechanisms ensuring such control are only starting to be explored, as demonstrated by the recent identification of a factor protecting regenerating tissues from cell fate changes. This is encoded by taranis, which regulates posterior cell fate during regeneration but seems dispensable in normal development (Schuster and Smith-Bolton 2015).

Several open questions remain in the regeneration field. The involvement of JNK has become clear, yet how it integrates with other pathways or genes that are differentially expressed in the blastema is unknown. Furthermore, the regulation conferring the plasticity of chromatin states necessary for cellular reprogramming depends on the $\mathrm{PcG} / \mathrm{TrxG}$ system, but little is known about the mechanisms ensuring a tightly regulated response at the chromatin level. Transdetermination studies have also contributed to our current understanding of regeneration, and similarities to human metaplasias have also been suggested since in both cases there are changes to the determined state of epithelial tissues that can be precursors to cancer (Maves and Schubiger 1999). It is, therefore, interesting to consider some similarities between regenerative responses and the early stages of tumor formation. It is plausible that damaging events in tissues initiate a regenerative response but lead to an unfaithful outcome if the route to the developmental program of choice is lost as a result of altered cellular plasticity. Regeneration and tumorigenesis could, therefore, be regarded as two sides of the same coin where the derailment of a repairing program could turn into a damaging response.

\section{Beyond physiology: imaginal discs as tumor models}

The normal functions of many genes identified as mutated in human cancers were first described in flies, and thus, Drosophila research has contributed substantially to our understanding of tumor biology. These genes include several components of the conserved signaling pathways mentioned thus far and also tumor suppressors like p53, NF1, APC, and $\mathrm{Rb}$. There are also examples of more direct contributions, where mutations lead to tumor formation in flies and have thus become known as fly tumor models. Interestingly, flies may also spontaneously develop tumors (found mostly in the testis and gut), and similar to humans, incidence increases with age (Salomon and Jackson 2008). Considering the short life expectancy, these observations might be unexpected but revealed the existence of tumors in normal fly strains. Here, however, the focus will be on tumors resulting from genetic manipulations, which can be informative for cancer biology across species. 
It has become clear that many human tumors result from one or more clonal events where cells lose their normal function and start overproliferating, often compromising the interactions with neighboring cells or the microenvironment. The initial steps that abnormal cells require to compromise homeostasis in their native tissue are poorly understood, since these early stages are not clinically accessible. Fortunately, Drosophila offers a significant advantage in this regard, where the behavior of only a few cells can be followed after inducing a trigger. In fact, the phenomenon of cell competition, which involves differential cell behavior within a tissue, has been observed and well documented for more than four decades in flies. The discovery of cell competition in Drosophila established a remarkable new concept to describe the survival and proliferation of cells with higher fitness at the expense of weaker neighbors. It was first observed in mosaics where heterozygous Minute $(M)$ cells are eliminated when surrounded by wild-type cells (Morata and Ripoll 1975). $M$ encodes a ribosomal component and $M$ homozygous mutant cells are lethal, but heterozygous animals are viable and cell competition only occurs when clones of cells with different fitness arise in close proximity (Johnston 2009; Martín et al. 2009; Morata and Ripoll 1975). Additional stimuli can also trigger cell competition, such as different doses of myc, yorkie, and others. Furthermore, cells seem to assess their fitness in a context-dependent manner (Vincent et al. 2013). For example, cells carrying only one copy of $m y c(m y c /+)$ are outcompeted by the surrounding wild-type cells. However, cells that carry an extra copy of myc $(m y c(+))$ can also outcompete wild-type cells, having become known as "supercompetitors" (de la Cova et al. 2004; Moreno and Basler 2004). Interestingly, the involvement of $m y c$ in cell competition has recently been described in the early mouse embryo as well, suggesting conserved features in mammals (Clavería et al. 2013). It is important to note that cell competition has direct implications in normal development, namely in growth regulation and maintenance of tissue homeostasis. Despite being a general phenomenon occurring in multicellular organisms, this process parallels several features that are required for cancer formation, where weaker cells are actively eliminated in response to signals originating from fast-growing cells that can take over more space to proliferate (Wagstaff et al. 2013).

In Drosophila, tumors have generally been categorized into hyperplastic or neoplastic (Bilder 2004; Gonzalez 2013). While imaginal discs carrying hyperplastic tumors show extensive overproliferation, they maintain relatively normal tissue organization with cells in a monolayer and can often differentiate into adult tissues. On the other hand, neoplastic tumors are more aggressive and the overproliferating cells lose their epithelial architecture. Forming multi-layers, these cells are able to grow uncontrollably and have limited differentiation capacity. The isolation of the first mutation causing tumorigenesis, lethal giant larvae (lgl), dates back to Bridges, but its malignant properties (cells growing rapidly and invasively, killing their host) were only reported in the 1960s. Mutations in two other genes, discs large (dlg) and scribble (scrib), were later identified to also lead to neoplastic tumors (Bilder and Perrimon 2000; Stewart et al. 1972). The three genes share phenotypic similarities where homozygous mutant larvae survive but keep growing as L3 for several days without reaching the pupal stage. Larvae size increases dramatically resembling "giant larvae," and finally will kill the host. These genes have become known as neoplastic tumor suppressor genes (nTSG).

Hyperplastic mutations exhibit uncontrolled proliferation, yet tissue architecture and differentiation capacity are still maintained. These phenotypes can be caused by inactivation of genes regulating cell growth, proliferation, or cell death, including many of the genes previously mentioned to regulate growth in a normal context, such as salvador, warts, hippo, fat (an atypical cadherin), expanded, Tscl/2, PTEN, or Csk (for details, see (Brumby and Richardson 2005; Hariharan and Bilder 2006; Harvey et al. 2013; Vidal and Cagan 2006)). More invasive tumors, in the neoplastic category, display cells that form rounded cyst-like patches, having lost the ability to maintain an epithelial monolayer crucial for tissue architecture and being unable to differentiate (Fig. 6). A common denominator was identified among $l g l, d l g$, and $s c r i b$ in that the proteins they encode interact with the cytoskeleton and define the apico-basal polarity that underlies epithelial cell function (Bilder et al. 2000). Therefore, cell polarity and architecture lie at the core of healthy physiology in epithelia, the tissue type where many human cancers also arise.

Identification of additional neoplastic tumor suppressor genes was facilitated by clonal analysis, as these mutations are lethal at earlier stages and larvae do not survive as long as for $\operatorname{lgl} / d l g / s c r i b$. Such nTSGs include avalanche, Rab5, tsg101, and vps 25 which play roles in endocytosis ( $\mathrm{Lu}$ and Bilder 2005; Moberg et al. 2005; Thompson et al. 2005; Vaccari and Bilder 2005; Wucherpfennig et al. 2003). In these mutants, inactivation of components of the endocytic machinery or ESCRT complexes compromise trafficking between different cellular compartments. There is a shared link between the endocytic and polarity-associated mutants, since failures in endocytosis lead to inappropriate accumulation of apical and basal proteins or signaling receptor molecules, which can mimic phenotypes of polarity nTSGs (Bilder 2004).

Although animals that are entirely mutant for nTSGs display giant larvae phenotypes, it became clear that scrib mutant clones could not outcompete their wild-type neighbor cells. Instead, these clones are progressively eliminated in a JNKdependent manner but can still become tumorigenic if JNK signaling is blocked (Brumby and Richardson 2003). Clonal studies, therefore, uncovered a cooperative effect between disruption of epithelial integrity and oncogenes, such as activated forms of Ras ( $\left.\mathrm{ras}^{\text {V12/act }}\right)$ and also Notch ${ }^{a c t}$. Although $\mathrm{ras}^{\text {act }}$ 


\section{Tumorigenesis Models}
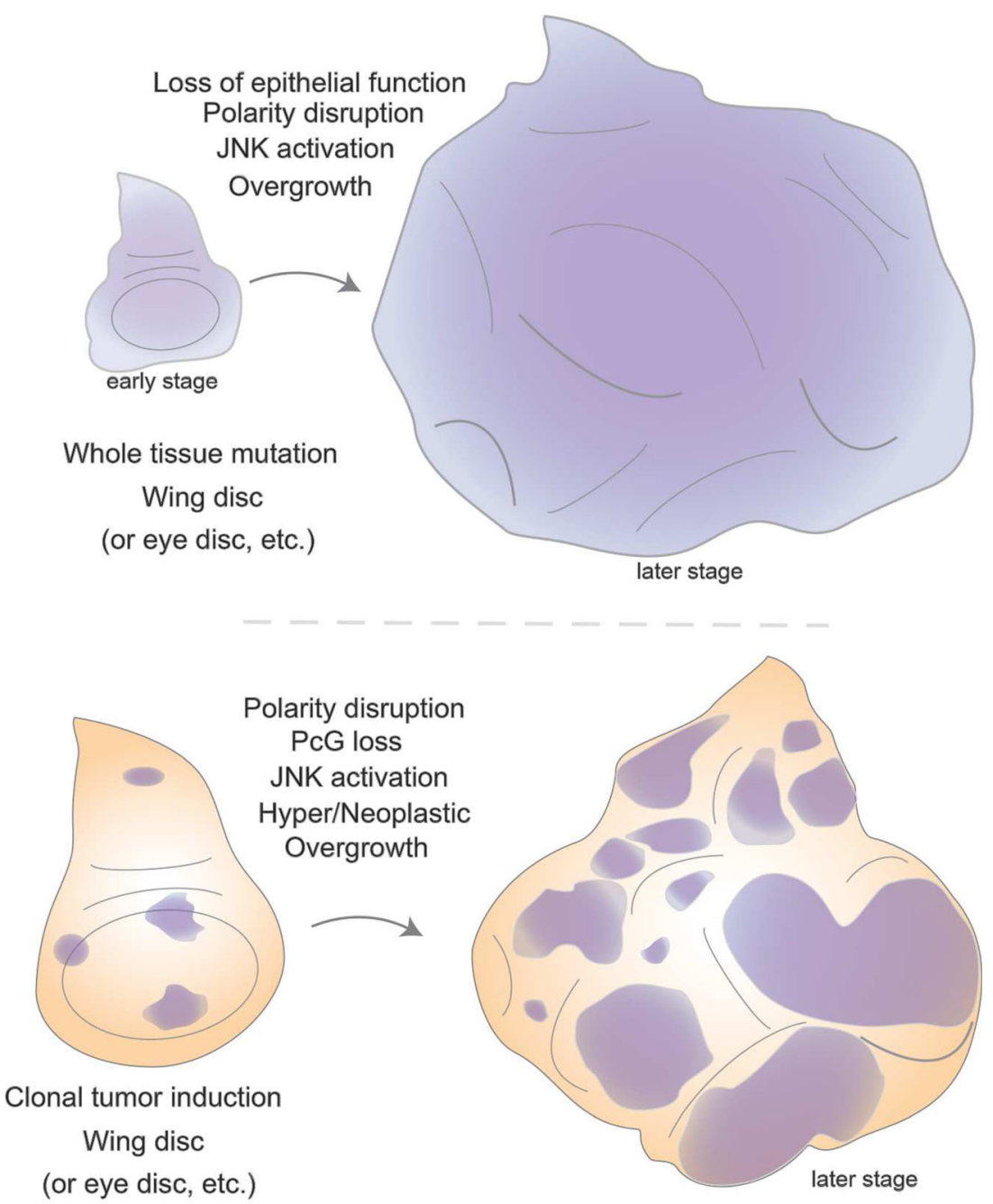

Fig. 6 Tumor models in Drosophila epithelial tissues. Powerful genetic screens revealed mutations in genes involved in tumorigenesis, namely some classes affecting the development of imaginal discs. Classical mutations like lgl (lethal giant larvae) displayed abnormal disc development where all tissues of homozygous individuals were affected (top). As larval development progresses, it becomes clear that the epithelial structure of disc tissues is aberrant with architectural defects leading to hyperplastic or neoplastic growth. Additional genes were later found to display similar phenotypes and share molecular functions as components of the apico-basal polarity machinery. The combination of mosaic analysis with gain- or loss-of-function experiments provided alternative means to fine-tune screening approaches. Clonal analysis (bottom) enables mutant patches to grow surrounded by wild-type

clones alone do not lead to neoplastic tumors (they result in overgrowth), combination with scrib clones leads to neoplastic phenotypes (Brumby and Richardson 2003). These observations prompted MARCM genetic screens in the eye disc to identify other factors involved in oncogenic cooperativity (both with ras $^{a c t}$ and Notch ${ }^{a c t}$ ). Examples include cytoskeletal components like rho/rhoGEF or the transcription factor abrupt (Brumby et al. 2011; Turkel et al. 2013). These tumors

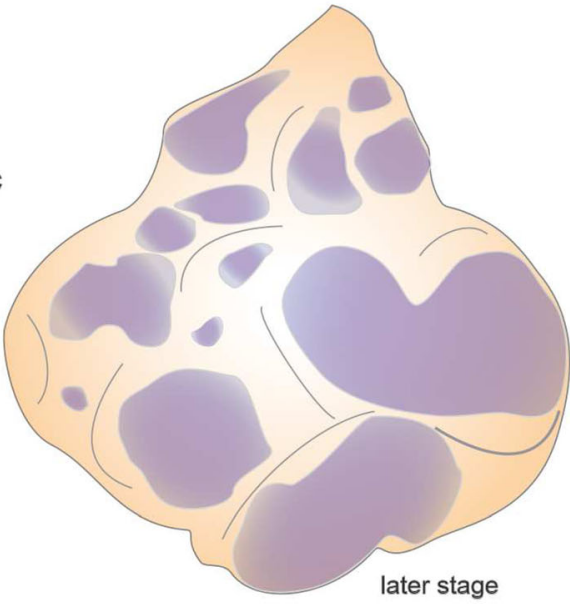

tissue, and thus, interactions between tumor and neighboring normal tissue can occur. These approaches revealed, in some instances, that cooperative interactions between conserved oncogenes and polarity determinants enhanced a tumorigenic phenotype in comparison to the effect of each component individually. On the other hand, mutations in epigenetic components (like $p h$, a Polycomb Group member) display strong neoplastic phenotypes in clones that also display abnormal epithelial architecture. Furthermore, the involvement of key signaling pathways is a common feature among fly epithelial tumors, suggesting that signaling events and potentially the interactions between healthy and tumor cells are likely to play a role in the disruptive events leading to tumor formation

also display a metastatic behavior, as some cells can invade the ventral nerve cord and distant portions of the central nervous system (Pagliarini and Xu 2003).

A common denominator of neoplastic tumors is ectopic stress signaling through JNK activation. Constitutive Ras signaling allows cells to survive by evading JNK-mediated apoptosis (Brumby and Richardson 2003). The invasiveness of scrib/ras ${ }^{\text {act }}$ clones depends on transcriptional activation of 
mmpl in a JNK-dependent manner, and changes in E-cadherin expression were also reported. These findings evoke a possible parallel with evidence from human tumors, which frequently have E-cadherin mutations, and the phenotypes of cancer tissue are reminiscent of alterations known as the epithelialmesenchymal transition (EMT) (Harvey et al. 2013; Igaki et al. 2006; Uhlirova and Bohmann 2006). Interestingly, neighboring scrib/ras ${ }^{a c t}$ clones can actively cooperate and metastasize, by forming interclonal tumors that seem to rely on loss of $s c r i b$ mostly during the early steps, as in later stages clones are mostly composed of $\mathrm{ras}^{\mathrm{VI2}}$-expressing cells (Wu et al. 2010). JAK-STAT activity has also been implied as an oncogenic driver in ras-mediated tumors. Overall, several aspects of these tumors exhibit features reminiscent of cell competition, hinting that it will be interesting to further investigate the parallels between competitive interactions in regulating normal growth or upon losing the ability to control it, leading to tumors (Levayer et al. 2015; Vincent et al. 2013).

Disruption of key chromatin regulators has also been shown to lead to tumorigenesis. Loss of polyhomeotic $(p h)$, a component of the Polycomb Repressive Complex 1 (PRC1), in eye disc clones results in massive overgrowth of eye and antennal tissue (Classen et al. 2009; Martinez et al. 2009). Clones induced by the MARCM technique (Fig. 4) display a severely disorganized architecture, loss of polarity, and some metastatic properties as well as aberrant signaling activities (Fig. 6). These tumors are dependent on JAK-STAT and Notch signaling activities, and have also been reported to lead to massive overproliferation in an RNAi screen for Notch regulators in the wing disc (Saj et al. 2010). Blocking these pathways ameliorates tumor burden, suggesting that the derailment of signaling pathways underlies a significant effect on the tumor phenotype (Feng et al. 2011, 2012). An overexpression screen for modifiers of Notch ${ }^{a c t}$ tumors uncovered a hit, named eyeful, which mapped within two genes (pipsqueak and longitudinals lacking) that produce transcription factors involved in the recruitment of Polycomb and chromatin complexes to promoter regions (Vallejo and Gutierrez-Aviño 2006).

Globally, fly tumor models display several phenotypes that parallel human cancer hallmarks, such as the ability to sustain overproliferation and growth, the capacity to evade apoptotic signals, the inability to respond to anti-proliferative signals, and the capability to metastasize to sites distant from their origin (Brumby and Richardson 2005; Gonzalez 2013). The use of transplantation techniques, pioneered several decades ago, became again instrumental to demonstrate the unlimited growth and survival of fly tumors in hosts, analogous to routine allograft experiments in mice (Rossi and Gonzalez 2015). It was demonstrated, for example, that ph tumor tissue does not accumulate genome instability even after prolonged cultivation. This suggests that an epigenetic derailment of gene expression control is sufficient to maintain neoplastic growth
(Sievers et al. 2014). There are, however, important limitations in that certain facets of human tumorigenesis are missing, since flies have a more rudimentary immune system and lack a closed circulatory system. These aspects restrict some direct comparisons with human cancer since angiogenesis and dedicated tumor immunological responses would not be easily modeled in flies. Nonetheless, the great advantages of fly research remain at the forefront in identifying the basic molecules that may have conserved roles which would otherwise be very difficult to find directly in mammals.

Namely, Drosophila's ability to contribute to the early steps of tumorigenesis has great potential, not only from the examples described here but also from emerging knowledge resulting from this very active research field. Many initial cancer triggers remain a mystery, which could be revealed from studies concerning key aspects of the observed fly tumor phenotypes. Moreover, it will be interesting to further explore the links between disrupted polarity, a common feature, as well as ectopic activation of several signaling cascades. An important open question entails how such pathways may influence the regulation of gene expression through transcription factors or chromatin regulators that exert global switches. These can, in a controlled fashion (like the regenerative process), result in faithful tissue organization, but when impaired, they may redefine cellular identities in a pathological manner.

\section{Conclusions and perspectives}

Imaginal discs are the Swiss army knife in Drosophila research, serving as versatile experimental systems to address a variety of scientific topics in cell and developmental biology. Here, we have covered a broad range of topics where the use of imaginal discs supported discoveries in cell and developmental biology, revealing conserved pathways and mechanisms. The use of these epithelial precursor organs has enabled functional studies in the context of a developing organism, benefitting from the implementation of genetic tools that considerably contributed to elucidating conserved molecular mechanisms.

With the emergence of new methods and technologies, the potential of imaginal discs as experimental systems remains unchallenged. The combination of established sophisticated tools with modern techniques promises to yield further contributions in developmental and cell biology. Research topics at the interface of physics and biology, like tissue mechanics, are having considerable progress in recent years by using imaginal discs to examine forces and cell interactions in their native tissues of origin. The improvement of long-term in vitro disc culture methods promises to bring many benefits to this field, and combination with other techniques such as live imaging, optogenetics, genome engineering (e.g., CRISPR/Cas9 coupled to homologous recombination), or tissue-specific 
protein-targeting nanobodies is expected to enable novel and cross-disciplinary discoveries that are yet unforeseen.

Despite the minute size of imaginal structures within the small fly, their contribution to answering fundamental questions has been immense, leading to a far-reaching insight across species. The conservation of many fly genes, proteins, and processes, together with developmental concepts common to all organisms, will provide profound implications for a better understanding of human development, physiology, and biomedicine going beyond measure.

Acknowledgments We thank P. Gaspar and S. Geisler for the discussions and comments on the manuscript and three anonymous reviewers for the suggestions leading to a significant improvement of the manuscript. We apologize to the many authors, whose papers we were not able to cite due to space restrictions.

Compliance with ethical standards This study was funded by grants from the Swiss National Science Foundation (grant numbers SNF 31003A_143922), Epigenesys, and the ETH Zurich. J.V.B. is supported by an EMBO long-term fellowship (ALTF1131-2014 and Marie Curie Actions LTFCOFUND2013/ GA-2013-609409).

Conflict of interest The authors declare that they have no conflict of interest.

Ethical approval This article does not contain any studies with human participants or animals performed by any of the authors.

Open Access This article is distributed under the terms of the Creative Commons Attribution 4.0 International License (http:// creativecommons.org/licenses/by/4.0/), which permits unrestricted use, distribution, and reproduction in any medium, provided you give appropriate credit to the original author(s) and the source, provide a link to the Creative Commons license, and indicate if changes were made.

\section{References}

Abbott LC, Karpen GH, Schubiger G (1981) Compartmental restrictions and blastema formation during pattern regulation in Drosophila imaginal leg discs. Dev Biol 87:64-75

Adams MD, Celniker SE, Holt RA, Evans CA, Gocayne JD, Amanatides PG, Scherer SE, Li PW, Hoskins RA, Galle RF et al (2000) The genome sequence of Drosophila melanogaster. Science 287:21852195

Affolter M, Basler K (2007) The Decapentaplegic morphogen gradient: from pattern formation to growth regulation. Nat Rev Genet 8:663674

Akiyama T, Gibson MC (2015) Decapentaplegic and growth control in the developing Drosophila wing. Nature 527:375-378

Aldaz S, Escudero LM, Freeman M (2010) Live imaging of Drosophila imaginal disc development. Proc Natl Acad Sci U S A 107:1421714222

Alexandre C, Baena-Lopez A, Vincent J-P (2014) Patterning and growth control by membrane-tethered Wingless. Nature 505:180-185

Ashe HL, Briscoe J (2006) The interpretation of morphogen gradients. Development 133:385-394
Beisel C, Paro R (2011) Silencing chromatin: comparing modes and mechanisms. Nat Rev Genet 12:123-135

Ben-Zvi D, Pyrowolakis G, Barkai N, Shilo B-Z (2011) Expansionrepression mechanism for scaling the Dpp activation gradient in Drosophila wing imaginal discs. Curr Biol 21:1391-1396

Bergantiños C, Corominas M, Serras F (2010a) Cell death-induced regeneration in wing imaginal discs requires JNK signalling. Development 137:1169-1179

Bergantiños C, Vilana X, Corominas M, Serras F (2010b) Imaginal discs: renaissance of a model for regenerative biology. Bioessays 32:207217

Bilder D (2004) Epithelial polarity and proliferation control: links from the Drosophila neoplastic tumor suppressors. Genes Dev 18:19091925

Bilder D, Perrimon N (2000) Localization of apical epithelial determinants by the basolateral PDZ protein Scribble. Nature 403:676-680

Bilder D, Li M, Perrimon N (2000) Cooperative regulation of cell polarity and growth by Drosophila tumor suppressors. Science 289:113-116

Blanco E, Ruiz-Romero M, Beltran S, Bosch M, Punset A, Serras F, Corominas M (2010) Gene expression following induction of regeneration in Drosophila wing imaginal discs expression profile of regenerating wing discs. BMC Dev Biol 10:94

Bosch M, Serras F, Martin-Blanco E, Baguñà J (2005) JNK signaling pathway required for wound healing in regenerating Drosophila wing imaginal discs. Dev Biol 280:73-86

Boyer LA, Plath K, Zeitlinger J, Brambrink T, Medeiros LA, Lee TI, Levine SS, Wernig M, Tajonar A, Ray MK et al (2006) Polycomb complexes repress developmental regulators in murine embryonic stem cells. Nature 441:349-353

Brand AH, Perrimon N (1993) Targeted gene expression as a means of altering cell fates and generating dominant phenotypes. Development 118:401-415

Bray S (1998) Notch signalling in Drosophila: three ways to use a pathway. Semin Cell Dev Biol 9:591-597

Brook WJ, Diaz-Benjumea FJ, Cohen S (1996) Organizing spatial pattern in limb development. Annu Rev Cell Dev Biol 12:161-180

Brumby AMA, Richardson HEH (2003) scribble mutants cooperate with oncogenic Ras or Notch to cause neoplastic overgrowth in Drosophila. EMBO J 22:5769-5779

Brumby AM, Richardson HE (2005) Using Drosophila melanogaster to map human cancer pathways. Nat Rev Cancer 5:626-639

Brumby AM, Goulding KR, Schlosser T, Loi S, Galea R, Khoo P, Bolden JE, Aigaki T, Humbert PO, Richardson HE (2011) Identification of novel ras-cooperating oncogenes in Drosophila melanogaster: a RhoGEF/Rho-Family/JNK pathway is a central driver of tumorigenesis. Genetics 188:105-125

Bryant PJ (1971) Regeneration and duplication following operations in situ on the imaginal discs of Drosophila melanogaster. Dev Biol 26: 637-651

Bryant PJ (1975) Regeneration and duplication in imaginal discs. Ciba Found Symp 29:71-93

Byrd KN, Shearn A (2003) ASH1, a Drosophila trithorax group protein, is required for methylation of lysine 4 residues on histone H3. Proc Natl Acad Sci U S A 100:11535-11540

Campbell G, Tomlinson A (1999) Transducing the Dpp morphogen gradient in the wing of Drosophila: regulation of Dpp targets by brinker. Cell 96:553-562

Capdevila J, Guerrero I (1994) Targeted expression of the signaling molecule decapentaplegic induces pattern duplications and growth alterations in Drosophila wings. EMBO J 13:4459-4468

Chen EH, Baker BS (1997) Compartmental organization of the Drosophila genital imaginal discs. Development 124:205-218

Chou TB, Perrimon N (1992) Use of a yeast site-specific recombinase to produce female germline chimeras in Drosophila. Genetics 131: $643-653$ 
Chou TB, Perrimon N (1996) The autosomal FLP-DFS technique for generating germline mosaics in Drosophila melanogaster. Genetics 144:1673-1679

Classen A-K, Bunker BD, Harvey KF, Vaccari T, Bilder D (2009) A tumor suppressor activity of Drosophila Polycomb genes mediated by JAK-STAT signaling. Nat Genet 41:1150-1155

Clavería C, Giovinazzo G, Sierra R, Torres M (2013) Myc-driven endogenous cell competition in the early mammalian embryo. Nature

Cohen S (1990) Specification of limb development in the Drosophila embryo by positional cues from segmentation genes. Nature 343: 173-177

Cohen S (1993) Imaginal disc development. In: Bate M, Martinez-Arias A (eds) The development of drosophila melanogaster. Cold Spring Harbor Laboratory Press

Cohen B, Wimmer EA, Cohen S (1991) Early development of leg and wing primordia in the Drosophila embryo. Mech Dev 33:229-240

Cohen B, Simcox AA, Cohen S (1993) Allocation of the thoracic imaginal primordia in the Drosophila embryo. Development 117:597608

Colombani J, Andersen DS, Léopold P (2012) Secreted peptide Dilp8 coordinates Drosophila tissue growth with developmental timing. Science 336:582-585

Crick FH, Lawrence PA (1975) Compartments and polyclones in insect development. Science 189:340-347

Czermin B, Melfi R, McCabe D, Seitz V, Imhof A, Pirrotta V (2002) Drosophila enhancer of Zeste/ESC complexes have a histone H3 methyltransferase activity that marks chromosomal Polycomb sites. Cell 111:185-196

Dahmann C, Basler K (1999) Compartment boundaries: at the edge of development. Trends Genet 15:320-326

Dahmann C, Oates AC, Brand M (2011) Boundary formation and maintenance in tissue development. Nat Rev Genet 12:43-55

de la Cova CC, Abril MM, Bellosta PP, Gallant PP, Johnston LAL (2004) Drosophila Myc regulates organ size by inducing cell competition. Cell 117:10

Diaz-Benjumea F (1993) Interaction between dorsal and ventral cells in the imaginal disc directs wing development in Drosophila. Cell 75: $741-752$

Dietzl G, Chen D, Schnorrer F, Su K-C, Barinova Y, Fellner M, Gasser B, Kinsey K, Oppel S, Scheiblauer S et al (2007) A genome-wide transgenic RNAi library for conditional gene inactivation in Drosophila. Nature 448:151-156

Estrada B, Casares F, Sánchez-Herrero E (2003) Development of the genitalia in Drosophila melanogaster. Differentiation 71:299-310

Fan Y, Bergmann A (2008) Distinct mechanisms of apoptosis-induced compensatory proliferation in proliferating and differentiating tissues in the Drosophila eye. Dev Cell 14:399-410

Feng S, Huang J, Wang J (2011) Loss of the Polycomb group gene polyhomeotic induces non-autonomous cell overproliferation. EMBO Rep 12:157-163

Feng S, Thomas S, Wang J (2012) Diverse tumor pathology due to distinctive patterns of JAK/STAT pathway activation caused by different Drosophila polyhomeotic alleles. Genetics 190:279-282

Fraser S, Keynes R, Lumsden A (1990) Segmentation in the chick embryo hindbrain is defined by cell lineage restrictions. Nature 344 : 431-435

Fristrom D, Fristrom JW (1993) The metamorphic development of the adult epidermis. In: Bate M, Martinez-Arias A (eds) The development of Drosophila melanogaster. Cold Spring Harbor Laboratory Press

Garcia-Bellido A, Merriam JR (1969) Cell lineage of the imaginal discs in Drosophila gynandromorphs. J Exp Zool 170:61-75

Garcia-Bellido A, Ripoll P, Morata G (1973) Developmental compartmentalisation of the wing disk of Drosophila. Nat New Biol 245:251-253
Garelli A, Gontijo AM, Miguela V, Caparros E, Dominguez M (2012) Imaginal discs secrete insulin-like peptide 8 to mediate plasticity of growth and maturation. Science 336:579-582

Gehring W (1972) The stability of the determined state in cultures of imaginal disks in Drosophila. In: Nöthiger R, Ursprung H (eds) The biology of imaginal disks. Heidelberg: Springer Berlin Heidelberg, Berlin, pp 35-58

Gehring WJ (2002) From transdetermination to the homeodomain at atomic resolution. An interview with Walter J Gehring. Int J Dev Biol 46:29-37

Golic KG, Lindquist S (1989) The FLP recombinase of yeast catalyzes site-specific recombination in the Drosophila genome. Cell 59:499 509

Gómez-Skarmeta JL, Campuzano S, Modolell J (2003) Half a century of neural prepatterning: the story of a few bristles and many genes. Nat Rev Neurosci 4:587-598

Gonzalez C (2013) Drosophila melanogaster: a model and a tool to investigate malignancy and identify new therapeutics. Nat Rev Cancer 13:172-183

Guruharsha KG, Kankel MW, Artavanis-Tsakonas S (2012) The Notch signalling system: recent insights into the complexity of a conserved pathway. Nat Rev Genet 13:654-666

Hadorn E (1965) Problems of determination and transdetermination. Brookhaven Symp Biol

Hamaratoglu F, de Lachapelle AM, Pyrowolakis G, Bergmann S, Affolter M (2011) Dpp signaling activity requires Pentagone to scale with tissue size in the growing Drosophila wing imaginal disc. PLoS Biol 9:e1001182

Hariharan IK, Bilder D (2006) Regulation of imaginal disc growth by tumor-suppressor genes in Drosophila. Annu Rev Genet 40:335361

Harmansa S, Hamaratoglu F, Affolter M, Caussinus E (2015) Dpp spreading is required for medial but not for lateral wing disc growth. Nature 527:317-322

Harvey KF, Zhang X, Thomas DM (2013) The Hippo pathway and human cancer. Nat Rev Cancer 13:246-257

Haynie JL, Bryant PJ (1986) Development of the eye-antenna imaginal disc and morphogenesis of the adult head in Drosophila melanogaster. J Exp Zool 237:293-308

Held LJ (2005) Imaginal discs. Cambridge University Press

Herrera SC, Morata G (2014) Transgressions of compartment boundaries and cell reprogramming during regeneration in Drosophila. Elife 3: e01831

Herrera SC, Martín R, Morata G (2013) Tissue homeostasis in the wing disc of Drosophila melanogaster: immediate response to massive damage during development. PLoS Genet 9:e1003446

Herz H-M, Chen Z, Scherr H, Lackey M, Bolduc C, Bergmann A (2006) vps 25 mosaics display non-autonomous cell survival and overgrowth, and autonomous apoptosis. Development 133:1871-1880

Hynes NE, Ingham PW, Lim WA, Marshall CJ, Massagué J, Pawson T (2013) Signalling change: signal transduction through the decades. Nat Rev Mol Cell Biol 14:393-398

Igaki T, Pagliarini RA, Xu T (2006) Loss of cell polarity drives tumor growth and invasion through JNK activation in Drosophila. Curr Biol 16:1139-1146

Ingham PW (1983) Differential expression of bithorax complex genes in the absence of the extra sex combs and trithorax genes. Nature 306: $591-593$

Ingham PWP, Arias AAM (1992) Boundaries and fields in early embryos. Cell 68:221-235

Jaeger J (2011) The gap gene network. Cell Mol Life Sci 68:243-274

Janody F, Martirosyan Z, Benlali A, Treisman JE (2003) Two subunits of the Drosophila mediator complex act together to control cell affinity. Development 130:3691-3701

Janody F, Lee JD, Jahren N, Hazelett DJ, Benlali A, Miura GI, Draskovic I, Treisman JE (2004) A mosaic genetic screen reveals distinct roles 
for trithorax and polycomb group genes in Drosophila eye development. Genetics 166:187-200

Jennings BH (2011) Drosophila - a versatile model in biology \& medicine. Mater Today 14:190-195

Jenny FH, Basler K (2015) Powerful drosophila screens that paved the wingless pathway. Fly (Austin) 0

Johnston LA (2009) Competitive interactions between cells: death, growth, and geography. Science 324:1679-1682

Johnston LA, Schubiger G (1996) Ectopic expression of wingless in imaginal discs interferes with decapentaplegic expression and alters cell determination. Development 122:3519-3529

Johnston LA, Prober DA, Edgar BA, Eisenman RN, Gallant P (1999) Drosophila myc regulates cellular growth during development. Cell 98:779-790

Kanca O, Caussinus E, Denes AS, Percival-Smith A, Affolter M (2014) Raeppli: a whole-tissue labeling tool for live imaging of Drosophila development. Development 141:472-480

Katsuyama T, Comoglio F, Seimiya M, Cabuy E, Paro R (2015) During Drosophila disc regeneration, JAK/STAT coordinates cell proliferation with Dilp8-mediated developmental delay. Proc Natl Acad Sci U S A 112:E2327-E2336

Kicheva A, Cohen M, Briscoe J (2012) Developmental pattern formation: insights from physics and biology. Science 338:210-212

Kiehle CP, Schubiger G (1985) Cell proliferation changes during pattern regulation in imaginal leg discs of Drosophila melanogaster. Dev Biol 109:336-346

Klebes A, Sustar A, Kechris K, Li H, Schubiger G, Kornberg TB (2005) Regulation of cellular plasticity in Drosophila imaginal disc cells by the Polycomb group, trithorax group and lama genes. Development 132:3753-3765

Kumar JP (2001) Signalling pathways in Drosophila and vertebrate retinal development. Nat Rev Genet 2:846-857

Lawrence PA (1992) The making of a fly: the genetics of animal design. Blackwell Scientific

Lawrence PA, Struhl G (1996) Morphogens, compartments, and pattern: lessons from Drosophila? Cell 85:951-961

Lee N, Maurange C, Ringrose L, Paro R (2005) Suppression of Polycomb group proteins by JNK signalling induces transdetermination in Drosophila imaginal discs. Nature 438:234-237

Levayer R, Hauert B, Moreno E (2015) Cell mixing induced by myc is required for competitive tissue invasion and destruction. Nature 524: 476-480

Levitt P, Barbe MF, Eagleson KL (1997) Patterning and specification of the cerebral cortex. Annu Rev Neurosci 20:1-24

Lewis EB (1978) A gene complex controlling segmentation in Drosophila. Nature 276:565-570

Lu H, Bilder D (2005) Endocytic control of epithelial polarity and proliferation in Drosophila. Nat Cell Biol 7:1232-1239

Madhavan MM, Schneiderman HA (1977) Histological analysis of the dynamics of growth of imaginal discs and histoblast nests during the larval development of Drosophila melanogaster. Wilhelm Roux Archiv 183:269-305

Maeda RK, Karch F (2015) The open for business model of the bithorax complex in Drosophila. Chromosoma 124:1-15

Mann RS, Morata G (2000) The developmental and molecular biology of genes that subdivide the body of Drosophila. Annu Rev Cell Dev Biol 16:243-271

Martin P, Parkhurst SM (2004) Parallels between tissue repair and embryo morphogenesis. Development 131:3021-3034

Martín FA, Herrera SC, Morata G (2009) Cell competition, growth and size control in the Drosophila wing imaginal disc. Development 136:3747-3756

Martinez A-M, Schuettengruber B, Sakr S, Janic A, Gonzalez C, Cavalli G (2009) Polyhomeotic has a tumor suppressor activity mediated by repression of Notch signaling. Nat Genet 41:1076-1082
Martinez-Arias A, Lawrence PA (1985) Parasegments and compartments in the Drosophila embryo. Nature 313:639-642

Mattila J, Omelyanchuk L, Kyttälä S, Turunen H, Nokkala S (2005) Role of Jun N-terminal kinase (JNK) signaling in the wound healing and regeneration of a Drosophila melanogaster wing imaginal disc. Int J Dev Biol 49:391-399

Maurange C, Paro R (2002) A cellular memory module conveys epigenetic inheritance of hedgehog expression during Drosophila wing imaginal disc development. Genes Dev 16:2672-2683

Maves L, Schubiger G (1995) Wingless induces transdetermination in developing Drosophila imaginal discs. Development 121:12631272

Maves L, Schubiger G (1998) A molecular basis for transdetermination in Drosophila imaginal discs: interactions between wingless and decapentaplegic signaling. Development 125:115-124

Maves L, Schubiger G (1999) Cell determination and transdetermination in Drosophila imaginal discs. Curr Top Dev Biol 43:115-151

McClure KD, Schubiger G (2007) Transdetermination: Drosophila imaginal disc cells exhibit stem cell-like potency. Int J Biochem Cell Biol 39:1105-1118

McClure KD, Schubiger G (2008) A screen for genes that function in leg disc regeneration in Drosophila melanogaster. Mech Dev 125:6780

McClure KD, Sustar A, Schubiger G (2008) Three genes control the timing, the site and the size of blastema formation in Drosophila. Dev Biol 319:68-77

Moberg KH, Bell DW, Wahrer DC, Haber DA, Hariharan IK (2001) Archipelago regulates Cyclin E levels in Drosophila and is mutated in human cancer cell lines. Nature 413:311-316

Moberg KH, Schelble S, Burdick SK, Hariharan IK (2005) Mutations in erupted, the Drosophila ortholog of mammalian tumor susceptibility gene 101, elicit non-cell-autonomous overgrowth. Dev Cell 9:699 710

Morata G (2001) How Drosophila appendages develop. Nat Rev Mol Cell Biol 2:89-97

Morata G, Lawrence PA (1975) Control of compartment development by the engrailed gene in Drosophila. Nature 255:614-617

Morata G, Ripoll P (1975) Minutes: mutants of drosophila autonomously affecting cell division rate. Dev Biol 42:211-221

Moreno EE, Basler KK (2004) dMyc transforms cells into super-competitors. Cell 117:13

Müller J, Hart CM, Francis NJ, Vargas ML, Sengupta A, Wild B, Miller EL, O'Connor MB, Kingston RE, Simon JA (2002) Histone methyltransferase activity of a Drosophila Polycomb group repressor complex. Cell 111:197-208

Mummery-Widmer JL, Yamazaki M, Stoeger T, Novatchkova M, Bhalerao S, Chen D, Dietzl G, Dickson BJ, Knoblich JA (2009) Genome-wide analysis of Notch signalling in Drosophila by transgenic RNAi. Nature 458:987-992

Nellen D, Burke R, Struhl G, Basler K (1996) Direct and long-range action of a DPP morphogen gradient. Cell 85:357-368

Neumann CJ, Cohen S (1997) Long-range action of Wingless organizes the dorsal-ventral axis of the Drosophila wing. Development 124: $871-880$

Nöthiger R (1972) The larval development of imaginal disks. In: Nöthiger R, Ursprung $H$ (eds) The biology of imaginal disks. Heidelberg: Springer Berlin Heidelberg, Berlin, pp 1-34

Nöthiger R (2002) Ernst Hadorn, a pioneer of developmental genetics

Pagliarini RA, Xu T (2003) A genetic screen in Drosophila for metastatic behavior. Science 302:1227-1231

Paro R, Hogness DS (1991) The Polycomb protein shares a homologous domain with a heterochromatin-associated protein of Drosophila. Proc Natl Acad Sci U S A 88:263-267

Poodry CA (1980) Imaginal discs: morphology and development. Genetics and Biology of Drosophila 
Postlethwait JH, Schneiderman HA (1973) Pattern formation in imaginal discs of Drosophila melanogaster after irradiation of embryos and young larvae. Dev Biol 32:345-360

Randsholt NB, Maschat F, Santamaria P (2000) polyhomeotic controls engrailed expression and the hedgehog signaling pathway in imaginal discs. Mech Dev 95:89-99

Ray RP, Arora K, Nüsslein-Volhard C, Gelbart WM (1991) The control of cell fate along the dorsal-ventral axis of the Drosophila embryo. Development 113:35-54

Repiso A, Bergantiños C, Serras F (2013) Cell fate respecification and cell division orientation drive intercalary regeneration in Drosophila wing discs. Development 140:3541-3551

Ringrose L, Paro R (2007) Polycomb/Trithorax response elements and epigenetic memory of cell identity. Development 134:223-232

Rossi F, Gonzalez C (2015) Studying tumor growth in Drosophila using the tissue allograft method. Nat Protoc 10:1525-1534

Saj A, Arziman Z, Stempfle D, van Belle W, Sauder U, Horn T, Dürrenberger M, Paro R, Boutros M, Merdes G (2010) A combined ex vivo and in vivo RNAi screen for Notch regulators in Drosophila reveals an extensive Notch interaction network. Dev Cell 18:862-876

Salomon RN, Jackson FR (2008) Tumors of testis and midgut in aging flies. Fly 2:265-268

Sánchez L, Guerrero I (2001) The development of the Drosophila genital disc. Bioessays 23:698-707

Schneuwly S, Gehring WJ (1985) Homeotic transformation of thorax into head: developmental analysis of a new Antennapedia allele in Drosophila melanogaster. Dev Biol 108:377-386

Schubiger G (1971) Regeneration, duplication and transdetermination in fragments of the leg disc of Drosophila melanogaster. Dev Biol 26: 277-295

Schubiger G, Schubiger M (1978) Distal transformation in Drosophila leg imaginal disc fragments. Dev Biol 67:286-295

Schubiger G, Schubiger-Staub M, Hadorn E (1969) Mischungsversuche mit Keimteilen vonDrosophila melanogaster zur Ermittlung des Determinationszustandes imaginaler Blasteme im Embryo. Wilhelm Roux Arch Entwickl Mech Org 163:33-39

Schubiger G, Schubiger M, Sustar A (2012) The three leg imaginal discs of Drosophila: "Vive la différence". Dev Biol 369:76-90

Schuster KJ, Smith-Bolton RK (2015) Taranis protects regenerating tissue from fate changes induced by the wound response in Drosophila. Dev Cell

Schwartz YB, Kahn TG, Nix DA, Li X-Y, Bourgon R, Biggin M, Pirrotta V (2006) Genome-wide analysis of Polycomb targets in Drosophila melanogaster. Nat Genet 38:700-705

Scott MP, Carroll SB (1987) The segmentation and homeotic gene network in early Drosophila development. Cell 51:689-698

Sexton T, Yaffe E, Kenigsberg E, Bantignies F, Leblanc B, Hoichman M, Parrinello H, Tanay A, Cavalli G (2012) Three-dimensional folding and functional organization principles of the Drosophila genome. Cell

Shearn A, Garen A (1974) Genetic control of imaginal disc development in Drosophila. Proc Natl Acad Sci U S A 71:1393-1397

Sievers C, Comoglio F, Seimiya M, Merdes G, Paro R (2014) A deterministic analysis of genome integrity during neoplastic growth in Drosophila. PLoS ONE 9:e87090

Smith-Bolton RK, Worley MI, Kanda H, Hariharan IK (2009) Regenerative growth in Drosophila imaginal discs is regulated by Wingless and Myc. Dev Cell 16:797-809

Spradling AC, Rubin GM (1982) Transposition of cloned P elements into Drosophila germ line chromosomes. Science 218:341-347

St Johnston D (2002) The art and design of genetic screens: Drosophila melanogaster. Nat Rev Genet 3:176-188

Stewart M, Murphy C, Fristrom JW (1972) The recovery and preliminary characterization of $\mathrm{X}$ chromosome mutants affecting imaginal discs of Drosophila melanogaster. Dev Biol 27:71-83

Struhl G (1982) Genes controlling segmental specification in the Drosophila thorax. Proc Natl Acad Sci U S A 79:7380-7384
Struhl G, Basler K (1993) Organizing activity of wingless protein in Drosophila. Cell 72:527-540

Tabata T (2001) Genetics of morphogen gradients. Nat Rev Genet 2:620 630

Tabata T, Takei Y (2004) Morphogens, their identification and regulation. Development 131:703-712

Tanaka EM, Reddien PW (2011) The cellular basis for animal regeneration. Dev Cell 21:172-185

Tapon N, Ito N, Dickson BJ, Treisman JE, Hariharan IK (2001) The Drosophila tuberous sclerosis complex gene homologs restrict cell growth and cell proliferation. Cell 105:345-355

Tapon N, Harvey KF, Bell DW, Wahrer DCR, Schiripo TA, Haber DA, Hariharan IK (2002) Salvador promotes both cell cycle exit and apoptosis in Drosophila and is mutated in human cancer cell lines. Cell 110:467-478

Thompson BJ, Cohen SM (2006) The Hippo pathway regulates the bantam microRNA to control cell proliferation and apoptosis in Drosophila. Cell 126:767-774

Thompson BJ, Mathieu J, Sung H-H, Loeser E, Rørth P, Cohen SM (2005) Tumor suppressor properties of the ESCRT-II complex component Vps25 in Drosophila. Dev Cell 9:711-720

Tolhuis B, Muijrers I, de Wit E, Teunissen H, Talhout W, van Steensel B, van Lohuizen M (2006) Genome-wide profiling of PRC1 and PRC2 Polycomb chromatin binding in Drosophila melanogaster. Nat Genet 38:694-699

Turkel N, Sahota VK, Bolden JE, Goulding KR, Doggett K, Willoughby LF, Blanco E, Martin-Blanco E, Corominas M, Ellul J et al (2013) The BTB-zinc finger transcription factor abrupt acts as an epithelial oncogene in Drosophila melanogaster through maintaining a progenitor-like cell state. PLoS Genet 9:e1003627

Uhlirova M, Bohmann D (2006) JNK- and Fos-regulated Mmp1 expression cooperates with Ras to induce invasive tumors in Drosophila. EMBO J 25:5294-5304

Vaccari T, Bilder D (2005) The Drosophila tumor suppressor vps 25 prevents nonautonomous overproliferation by regulating Notch trafficking. Dev Cell 9:687-698

Vallejo DM, Gutierrez-Aviño FJ (2006) Epigenetic silencers and Notch collaborate to promote malignant tumours by $\mathrm{Rb}$ silencing. Nature 439:430-436

Vidal M, Cagan RL (2006) Drosophila models for cancer research. Curr Opin Genet Dev 16:10-16

Vincent JP, Briscoe J (2001) Morphogens. Curr Biol 11:R851-R854

Vincent JP, O'Farrell PH (1992) The state of engrailed expression is not clonally transmitted during early Drosophila development. Cell 68: 923-931

Vincent J-P, Fletcher AG, Baena-Lopez LA (2013) Mechanisms and mechanics of cell competition in epithelia. Nat Rev Mol Cell Biol 14: $581-591$

Vuilleumier R, Springhorn A, Patterson L, Koidl S, Hammerschmidt M, Affolter M, Pyrowolakis G (2010) Control of Dpp morphogen signalling by a secreted feedback regulator. Nat Cell Biol 12:611-617

Wagstaff L, Kolahgar G, Piddini E (2013) Competitive cell interactions in cancer: a cellular tug of war. Trends Cell Biol 23:160-167

Wangler MF, Yamamoto S, Bellen HJ (2015) Fruit flies in biomedical research. Genetics 199:639-653

Wartlick O, Mumcu P, Jülicher F, González-Gaitán M (2011) Understanding morphogenetic growth control-lessons from flies. Nat Rev Mol Cell Biol 12:594-604

Wei G, Schubiger G, Harder F, Müller AM (2000) Stem cell plasticity in mammals and transdetermination in Drosophila: common themes? Stem Cells 18:409-414

Whiteley M, Noguchi PD, Sensabaugh SM, Odenwald WF, Kassis JA (1992) The Drosophila gene escargot encodes a zinc finger motif found in snail-related genes. Mech Dev 36:117-127

Wieschaus E, Gehring W (1976) Clonal analysis of primordial disc cells in the early embryo of Drosophila melanogaster. Dev Biol 50:249-263 
Williams JA, Bell JB, Carroll SB (1991) Control of Drosophila wing and haltere development by the nuclear vestigial gene product. Genes Dev 5:2481-2495

Worley MI, Setiawan L, Hariharan IK (2012) Regeneration and transdetermination in Drosophila imaginal discs. Annu Rev Genet 46:289-310

Wu S, Huang J, Dong J, Pan D (2003) hippo encodes a Ste-20 family protein kinase that restricts cell proliferation and promotes apoptosis in conjunction with salvador and warts. Cell 114:445-456

Wu M, Pastor-Pareja JC, Xu T (2010) Interaction between Ras(V12) and scribbled clones induces tumour growth and invasion. Nature 463: $545-548$
Wucherpfennig T, Wilsch-Bräuninger M, González-Gaitán M (2003) Role of Drosophila Rab5 during endosomal trafficking at the synapse and evoked neurotransmitter release. J Cell Biol 161:609-624

$\mathrm{Xu}$ T, Wang W, Zhang S, Stewart RA, Yu W (1995) Identifying tumor suppressors in genetic mosaics: the Drosophila lats gene encodes a putative protein kinase. Development 121: 1053-1063

Zecca M, Basler K, Struhl G (1995) Sequential organizing activities of engrailed, hedgehog and decapentaplegic in the Drosophila wing. Development 121:2265-2278

Zecca M, Basler K, Struhl G (1996) Direct and long-range action of a wingless morphogen gradient. Cell 87:833-844 